\title{
A novel short splice variant of the tumour suppressor LKB1 is required for spermiogenesis
}

\author{
Mhairi C. Towler ${ }^{*}$, Sarah Fogarty ${ }^{*}$, Simon A. Hawley ${ }^{*}$, David A. Pan ${ }^{*}$, , David M. A. Martin ${ }^{\dagger}$, \\ Nicolas A. Morriceł, Afshan McCarthy§, María N. Galardo", Silvina B. Meroni", Selva B. \\ Cigorraga", Alan Ashworth ${ }^{\S}$, Kei Sakamotoł and D. Grahame Hardie ${ }^{* 1}$
}

*Division of Molecular Physiology, ${ }^{\dagger}$ Post-Genomics and Molecular Interactions Centre and ¥MRC Protein Phosphorylation Unit, College of Life Sciences, University of Dundee, Dundee, Scotland, UK; ${ }^{\S}$ The Breakthrough Breast Cancer Research Centre, The Institute of Cancer Research, Fulham Rd, London SW3 6JB, UK; "Centro de Investigaciones Endocrinológicas (CEDIE-CONICET), Argentina

Ipresent address: Prosidion Limited, Windrush Court, Watlington Road, Oxford OX4 6LT, UK

${ }^{1}$ to whom correspondence should be addressed at: Division of Molecular Physiology, School of Life Sciences, University of Dundee, Dow Street, Dundee, DD1 5EH, Scotland, UK; e-mail: d.g.hardie@dundee.ac.uk; Tel: +44 (1382) 344253; FAX: +44 (1382) 345783

Running Head: LKB1 splice variants - role in spermiogenesis 


\section{SYNOPSIS}

LKB1 was discovered as a tumour suppressor mutated in Peutz-Jeghers syndrome and a gene involved in cell polarity, and is an upstream protein kinase for members of the AMP-activated protein kinase family. We report that mammals express two splice variants caused by alternate usage of 3 '-exons. $\mathrm{LKB} 1_{\mathrm{L}}$ is the previously described form, while $\mathrm{LKB} 1_{\mathrm{S}}$ is a novel form in which the last 63 residues are replaced by a unique 39-residue sequence lacking known phosphorylation (Ser-431) and farnesylation (Cys-433) sites. Both isoforms are widely expressed in rodent and human tissues, although $\mathrm{LKB} 1_{\mathrm{S}}$ is particularly abundant in haploid spermatids in the testis. Male mice in which expression of $\mathrm{Lkb}_{\mathrm{S}}$ is knocked out are sterile, with the number of mature spermatozoa in the epididymis being dramatically reduced, and those spermatozoa that are produced having heads with an abnormal morphology, and being non-motile. These results identify a previously undetected variant of LKB1, and suggest that it has a crucial role in spermiogenesis and male fertility.

KEYWORDS: AMP-activated protein kinase, AMPK, LKB1, male fertility, spermiogenesis, splice variants 


\section{INTRODUCTION}

The LKB1 (STK11) gene, encoding a tumour suppressor protein kinase, was discovered as the gene mutated in human Peutz-Jeghers syndrome (PJS), a cancer predisposition that is inherited in an autosomal dominant manner [1,2]. PJS subjects develop numerous benign polyps in the gastrointestinal tract and have a 20 -fold increased risk of developing malignant tumours at other sites, while mutations in the $L K B 1$ gene are also seen in some sporadic cancers, especially adenocarcinoma of the lung [3]. Several human tumour cell lines lack LKB1, and expression of the protein in these cells causes a G1 cell cycle arrest. Homozygous $L k b 1^{-/-}$knockout mice die at midgestation, while heterozygous mice develop intestinal lesions similar to those found in humans with PJS [3]. Thus, analysis of heterozygous mutations in mammalian species suggest that LKB1 has a role in restraining cell growth and proliferation. Genetic studies in other eukaryotes such as Caenorhabditis elegans and Drosophila melanogaster have suggested another function, i.e. that LKB1 has a role in the establishment and/or maintenance of cell polarity. In C. elegans, a maternal effect lethal mutation in the LKB1 orthologue, par-4, disrupts the normal asymmetry in the first cell cycles of embryogenesis [4]. Mutations in the D. melanogaster orthologue, dLKB1, cause defects in cell polarity in the oocyte and the developing embryo [5, 6].

Important insights into the biochemical function of LKB1 came with the discovery that it is an upstream kinase that phosphorylates the activation loop of protein kinases of the AMP-activated protein kinase (AMPK) family. These include the $\alpha 1$ and $\alpha 2$ isoforms of AMPK itself [7-9], as well as at least twelve AMPK-related kinases $[10,11]$. AMPK exists as heterotrimeric complexes formed from catalytic $\alpha$ subunits and regulatory $\beta$ and $\gamma$ subunits, each of which has multiple isoforms encoded by distinct genes [12]. LKB1 phosphorylates Thr-172 on the catalytic $\alpha$ subunits of AMPK, and the equivalent threonine on the AMPK-related kinases, causing in every case a large activation. Whether activation of AMPK accounts for the tumour suppressor properties of LKB1 remains uncertain. However, AMPK activation inhibits the TOR pathway [13, 14], thus inhibiting cell growth, and also causes a G1 $\rightarrow$ S phase cell cycle arrest in cultured cells, an effect that involves increased phosphorylation of p53 $[15,16]$. Also consistent with the idea that AMPK mediates the tumour suppressor functions of LKB1 are findings that the TOR pathway is hyperactive in intestinal lesions from $L k b 1^{+/-}$heterozygous mice [17], and that pharmacological activators of AMPK reduce tumour formation in a cancer-prone mouse model that is heterozygous for PTEN and has a hypomorphic mutation in LKB1 [18].

The role of LKB1 in establishment of cell polarity may also involve activation of AMPK, because null mutations in the LKB1 and AMPK genes in D. melanogaster cause similar defects in polarity of epithelial cells in the developing embryo [6]. Activation of either LKB1 or AMPK in cultured intestinal or kidney epithelial cells also triggers establishment of cell polarity [6, 19-21]. However, several of the kinases downstream of LKB1 also appear to have functions in cell polarity, including the MARKS [22], which are homologues of C. elegans PAR-1, and BRSK1/BRSK2 (SAD-B/SAD-A) [23], which are homologues of C. elegans SAD-1.

LKB1 exists in vivo as a complex with two accessory subunits, i.e. STRAD (Ste20-related adaptor), which is essential for LKB1 activity, and MO25 (mouse protein 25), which appears to stabilize the LKB1:STRAD complex [3]. At least 75 mutations affecting the amino acid sequence of LKB1 have been found in PJS subjects and in sporadic cancers. Most either directly interfere with the kinase activity, or abolish it indirectly by preventing interaction with STRAD. However, a significant number (around 20\%) affect the C-terminal region of LKB1 where they do not appear to affect kinase activity or STRAD interaction [3]. 
In this study, we report that the C-terminal region of LKB1 is affected by alternative splicing to produce long and short variants of the $\mathrm{LKB} 1$ polypeptide $\left(\mathrm{LKB} 1_{\mathrm{L}}\right.$ and $\left.\mathrm{LKB} 1_{\mathrm{S}}\right)$ that have different C-terminal sequences. $\mathrm{LKB} 1_{\mathrm{S}}$, which lacks the Ser-431 site and the farnesylation site, is a minor form in most tissues, but is highly abundant in haploid spermatids in the testis. Both $\mathrm{LKB} 1_{\mathrm{L}}$ and $\mathrm{LKB} 1_{\mathrm{S}}$ are capable of activating AMPK and all of the AMPK-related kinases tested. However, male mice that cannot generate $\mathrm{Lkb} 1_{\mathrm{S}}$ are sterile, and produce dramatically reduced numbers of mature spermatozoa that are non-motile and have abnormal morphology.

\section{MATERIALS AND METHODS}

\section{Cloning and expression of rat $L K B 1_{S}$ and $L K B 1_{L}$ and other plasmids}

Based on a rat EST (BF396918) that encoded the last 11 amino acids of $\mathrm{LKB} 1_{\mathrm{L}}$, followed by a 3'UTR and poly(A) tail, we designed a reverse primer (5'-tggcgacacactgttggtagaatg-3'), while the forward primer (5'-gaacttgaaaagaattggcgetcc-3') was based on a sequence $50 \mathrm{bp}$ upstream of the initiator ATG codon in rat, based on results of 5'-RACE. These were used to generate full-length rat LKB1 $1_{L}$ DNA by reverse transcriptase-polymerase chain reaction (RT-PCR) using the Titan One Tube RT-PCR kit (Roche Diagnostics) with the rat brain RNA as template. The product was gel purified, ligated into pGEM-T Easy (Promega), and used to transform TOP10F' E. coli. Colonies were picked and it was confirmed that they contained the full-length rat $\mathrm{LKB} 1_{\mathrm{L}}$ sequence. A 1700 bp EcoRI/SpeI fragment was ligated into pcDNA3.1/Zeo. Searching of the NCBI database revealed a rat testis EST (CK597755) that encoded the C-terminal region of LKB1 $1_{S}$ plus 52 bp of 3'-UTR and a poly(A) tail. This was purchased from the IMAGE consortium. The insert was $\approx 1700 \mathrm{bp}$, and sequencing revealed that it encoded the full-length $L K B 1_{S}$ sequence. The insert was also sub-cloned into pcDNA3.1/Zeo. For the glutathione-S-transferase (GST) fusions, $\mathrm{LKB} 1_{\mathrm{L}}$ and $\mathrm{LKB} 1_{\mathrm{S}} \mathrm{DNAs}$ were amplified from the pcDNA3.1 vectors for subcloning into pEBG2T as a Spe1-Kpn1 insert using the forward primer 5'-cggactagtccgatggacgtggetgaccccag-3' and reverse primers 5'-cggggtacccegtcactgctgcttgcaggccga-3' $\left(\mathrm{LKB}_{\mathrm{L}}\right)$ and 5'-cggggtaccccgtcacagtggacaaagctttat-3' $\left(\mathrm{LKB} 1_{\mathrm{S}}\right)$.

\section{Antibodies}

The anti-LKB1(N) antibody was raised against the peptide TFIHRIDSTEVIYQP (residues 24-36 of human, mouse and rat LKB1) [24]. Although raised against the peptide phosphorylated on Ser-31, the antibody was affinity purified on a column containing the dephosphopeptide (with an $\mathrm{N}$ terminal cysteine, coupled via the thiol group to $\mathrm{CH}$-Sepharose $4 \mathrm{~B}$ (Pharmacia) as described previously [25]). The purified antibody does not appear to be dependent on the phosphorylation state of Ser-31 because it recognizes an S31A mutant as well as wild type LKB1. The anti-LKB1 $1_{\mathrm{L}}$ antibody was raised in sheep against the peptide KIRRLSACKQQ (residues 423-436 of rat LKB1 $1_{\mathrm{L}}$, with a farnesyl group on Cys-433), and was affinity purified on a column containing the defarnesylated peptide. Although this antibody was raised in an attempt to develop an antibody that was dependent on farnesylation status, when purified in this manner it appears to be farnesylationindependent, because it recognizes an C433A mutant as well as wild type $\mathrm{LKB} 1_{\mathrm{L}}$. The anti-LKB1 antibody was raised in sheep against the peptide CGLPGEEPEEGFGAVV (residues 398-412 of rat LKB1 $1_{\mathrm{S}}$ plus N-terminal cysteine) using methods described previously [25]. MARK3 antibodies were from Upstate Biotech (\#05-680) and anti-pT172 and anti-myc antibodies from Cell Signalling Technology (\#2535L and \#2276). Antibodies against SIK1 (SIK), SIK2 (QIK), SIK3 (QSK), 
NUAK2 and MARK1 [10], AMPK- $\alpha 1$ and - $\alpha 2$ [26], GST [27], and a monoclonal antibody against STRAD $\alpha$ were as described previously [28].

\section{Bioinformatic analysis of LKB1 sequences}

LKB1 peptide sequences (Q15831, human; Q9WTK7, mouse; XP_234900, rat [two versions]) were obtained from the Uniprot and RefSeq databases using a keyword search, and used as probes to search the human, mouse and rat genome databases at ensEMBL. A strong hit was noted for LKB1 in each genome on chromosome 19 (human), 10 (mouse) and 7 (rat). Each LKB1 sequence was aligned against the respective genomic sequence using EXONERATE

[http://www.ebi.ac.uk/ guy/exonerate/] and putative intron/exon boundaries identified for $\mathrm{LKB} 1_{\mathrm{L}}$ in rat, mouse and human. Alignment of the sequence for rat $\mathrm{LKB} 1_{\mathrm{S}}$ allowed the putative intron/exon boundaries for intron 8 to be identified in rat and mouse. The human sequence for exon 9A shows only partial similarity to rat and mouse and was not identified by this method. Instead, rat exon 9A sequence, as verified through EST evidence (see below) was aligned with the human genomic sequence using TBLASTN, and the putative intron/exon boundaries identified by manual inspection of the location of the short match in the context of three frame translations and splice sites.

Intron/exon boundaries were verified by alignment of EST sequences with the genomic sequence for all three species. BLAST [29] searches of dbEST using the protein sequences and fragments of the genomic sequence identified EST sequences corresponding to full coverage of all forms of the protein in all species. At least two ESTs were found for each form of the protein in each species. The EST sequences were manually aligned with the genomic sequence using the Jalview multiple sequence alignment editor [30]. There is an additional intron (intron 10) in the mRNA coding for the long form of the protein, $3^{\prime}$ to the translation stop codon, which is conserved across all three species.

\section{Rapid Amplification of cDNA Ends}

Rapid Amplification of cDNA Ends (3'-RACE) was carried out using the Marathon cDNA Amplification Kit (Clontech), using as template Marathon Ready rat testis cDNA (Clontech Cat. \#639417). 3'-RACE was carried out using the forward gene-specific primer ttgacggcctggagtacctacaca (encoding residues 161-168 in the common region). This gave rise to two products, a major product of $830 \mathrm{bp}$ and a minor product of about $560 \mathrm{bp}$. These were gel purified and re-amplified by a second round of PCR. Sequencing of the $830 \mathrm{bp}$ product using the primer gagtacgagccagccaagag yielded a sequence encoding residues 330-412 of LKB $1_{\mathrm{s}}$. Sequencing of the $560 \mathrm{bp}$ product using the primer gtcacactctacaaccatcaccacg yielded a sequence encoding residues 291-406 of LKB1 $1_{\mathrm{L}}$.

\section{Immunoprecipitation of rat testis LKB1 and analysis by mass spectrometry}

LKB1 was purified to the Q-Sepharose stage from rat testis as described previously for rat liver [7] and fractions containing both $\mathrm{LKB} 1_{\mathrm{L}}$ and $\mathrm{LKB} 1_{\mathrm{S}}$ identified by Western blotting. These fractions (3.75 mg protein) were immunoprecipitated using antibody against GST-LKB1 [31] covalently conjugated to protein G-Sepharose using dimethylpimelimidate [32]. After extensive washing, bound protein was eluted using $1 \% \mathrm{SDS}$ in $20 \mathrm{mM}$ Tris/HCl, $\mathrm{pH}$ 7.5. Samples were concentrated 10 -fold using a Speedivac concentrator, and protein precipitated overnight using 10 vols ice-cold methanol. After centrifugation $(16,000 \mathrm{~g}, 15 \mathrm{~min})$ the precipitate was resuspended in SDS sample buffer, proteins resolved by SDS-PAGE on a 4-12\% pre-cast gradient gel using the MOPS buffer system (Invitrogen) and visualised by staining with Colloidal Coomassie Blue. Stained polypeptides 
were destained, digested with trypsin and analysed by mass spectrometry using an Applied Biosystems 4700 Proteomics Analyser [33]. Digests were also analysed by liquid chromatographyelectrospray mass spectrometry (LCMS) using an Applied Biosystems 4000 Q-TRAP mass spectrometer [34].

\section{Immunoprecipitation and Western blotting of LKB1 from various tissue extracts}

Male rats (Wistar) or mice were anesthetized using $\mathrm{CO}_{2}$ and sacrificed by cervical dislocation. The indicated tissues were rapidly removed, frozen in liquid $\mathrm{N}_{2}$ and stored at $-80^{\circ} \mathrm{C}$ until used. Tissue samples were pulverised under liquid $\mathrm{N}_{2}$ and homogenised in a hand held homogeniser on ice in lysis buffer (50 mM Tris/HCl pH 7.5, $50 \mathrm{mM} \mathrm{NaF}, 1 \mathrm{mM}$ Na pyrophosphate, $1 \mathrm{mM}$ EDTA, $1 \mathrm{mM}$ EGTA, $1 \%$ Triton X-100, 1mM DTT, $0.1 \mathrm{mM}$ PMSF, $1 \mathrm{mM}$ benzamidine and $1 \mu \mathrm{g} / \mathrm{ml}$ soybean trypsin inhibitor). Homogenates were centrifuged $\left(13,000 \mathrm{~g}, 15 \mathrm{~min}, 4^{0} \mathrm{C}\right)$, supernatants removed, frozen in liquid $\mathrm{N}_{2}$ and stored at $-80^{\circ} \mathrm{C}$ until used. Samples (20 or $200 \mu \mathrm{g}$ protein) were incubated at $4^{0} \mathrm{C}$ for $2 \mathrm{hr}$ on a shaking platform with $5 \mu \mathrm{l}$ of protein G-Sepharose covalently conjugated (using dimethyl pimelimidate) to $10 \mu \mathrm{g}$ of anti-LKB1(N) antibody. After extensive washing, the immunoprecipitates were heated in SDS sample buffer, resolved by SDS-PAGE and blots probed the indicated antibodies.

Human protein medleys (10 mg/ml in SDS sample buffer) from brain, heart, liver and testes were from Clontech. They were resolved by SDS-PAGE without prior immunoprecipitation and analysed by Western blotting with the indicated antibodies.

For Figs. 3D and 6B/C, homogenates were prepared from rat or mouse testis and epididymis by grinding tissue under liquid $\mathrm{N}_{2}$ and adding an equal vol. of homogenisation buffer (50 mM Tris, $\mathrm{pH}$ 7.3, 1 mM EDTA, 1 mM EGTA, $50 \mathrm{mM} \mathrm{NaCl}, 5 \mathrm{mM}$ Na pyrophosphate, $50 \mathrm{mM} \mathrm{NaF}, 2 \mathrm{mM}$ dithiothreitol (DTT), $1 \mathrm{mM}$ phenylmethane sulphonylfluoride (PMSF), $2 \mathrm{mM}$ benzamidine, $1 \%$ Triton X-100, $250 \mathrm{mM}$ mannitol) and homogenising using a Dounce homogeniser. Samples were left on ice for $30 \mathrm{~min}$, followed by a second bout of homogenisation before being centrifuged at $14,000 \mathrm{rpm}\left(4^{\circ} \mathrm{C}\right)$ and the supernatant used for immunoprecipitation or analysis by Western blotting. For preparation of spermatozoa extract, the epididymis was chopped finely in PBS and centrifuged $\left(3,000 \mathrm{rpm}, 2 \mathrm{~min}, 4^{\circ} \mathrm{C}\right)$. The supernatant was centrifuged again $\left(14,000 \mathrm{rpm}, 4^{\circ} \mathrm{C}, 5\right.$ $\mathrm{min})$. The pellet containing the spermatozoa was lysed in $50 \mu \mathrm{l}$ of homogenisation buffer and left on ice for $30 \mathrm{~min}$, followed by centrifugation $\left(14000 \mathrm{rpm}, 5 \mathrm{~min}, 4^{\circ} \mathrm{C}\right)$. The supernatant was analysed by Western blotting.

\section{Isolation of tRNA from mouse testis and RT-PCR}

tRNA was extracted from $\mathrm{LKB} 1^{+/+}$and $\mathrm{LKB} 1^{\mathrm{fl} / \mathrm{fl}}$ mice testis as follows: $1 \mathrm{ml}$ Trizol reagent (Invitrogen) was added to tissue in a tube containing lysing matrix D (small ceramic beads) and placed on ice. Tissue was homogenised using the Precellys 24 machine (Bertin Technologies) at $6,000 \mathrm{rpm}$ for 20 seconds, twice. Tubes were left on ice for $5 \mathrm{~min}$, chloroform (200 $\mu \mathrm{l})$ was added, tubes vortexed for $1 \mathrm{~min}$ and then centrifuged $\left(12,000 \mathrm{rpm}, 15 \mathrm{~min}, 4^{\circ} \mathrm{C}\right)$. Isopropanol $(500 \mu \mathrm{l})$ was added to the supernatant and the tube inverted and left at room temp for $10 \mathrm{~min}$. Tubes were centrifuged $\left(14,000 \mathrm{rpm}, 10 \mathrm{~min}, 4^{\circ} \mathrm{C}\right)$, the supernatant removed, the pellet washed twice in $80 \%$ ethanol and left to air-dry before being dissolved in diethylpyrocarbonate-treated water. tRNA was then purified using the DNA-free kit (Ambion) and RT-PCR carried out using the Promega Access Quick RT-PCR system. 


\section{Expression of LKB1 complexes and activation of AMPK-related kinases in HeLa cells}

HeLa cells were cultured in DMEM containing 10\% FBS and 1x penicillin/streptomycin solution (Invitrogen). Cells cultured on $10 \mathrm{~cm}$ dishes were transfected with $3 \mu \mathrm{g}$ of $\mathrm{LKB} 1_{\mathrm{L}}$ or $\mathrm{LKB} 1_{\mathrm{S}}$ plasmid and $3 \mu \mathrm{g}$ of each of FLAG-STRAD $\alpha$ and $m y c-M O 25 \alpha$ plasmids using the polyethylenimine method [35]. The cells were cultured for a further $36 \mathrm{hr}$ and lysed in $0.5 \mathrm{ml}$ of ice-cold lysis buffer (50 mM Tris/HCl, pH 7.2, 1 mM EGTA, $1 \mathrm{mM}$ EDTA, $50 \mathrm{mM} \mathrm{NaF}, 1 \mathrm{mM} \mathrm{Na}$ pyrophosphate, $1 \%(\mathrm{w} / \mathrm{v})$ Triton-X 100, $0.1 \mathrm{mM}$ PMSF, $1 \mathrm{mM}$ DTT, $0.1 \mathrm{mM}$ benzamidine and 5 $\mu \mathrm{g} / \mathrm{ml}$ soybean trypsin inhibitor) after quick rinsing in phosphate-buffered saline (PBS). The lysates were centrifuged at $4^{\circ} \mathrm{C}$ for $10 \mathrm{~min}$ at $13,000 \mathrm{rpm}$.

For immunoprecipitate kinase assays, $\left(0.1-1 \mathrm{mg}\right.$ protein) was incubated at $4^{\circ} \mathrm{C}$ for $2 \mathrm{hr}$ on a shaker with $5 \mu \mathrm{g}$ of the appropriate antibody previously conjugated to $5 \mu \mathrm{l}$ of protein G-Sepharose. Kinase activity was then determined as described previously [36] using the AMARA peptide [37] as substrate.

\section{Bacterial expression of the kinase domains of AMPK- $\alpha 1$, BRSK1 and BRSK2} Plasmids encoding GST fusions of the kinase domains of rat AMPK- $\alpha 1$ (residues 1-312), BRSK1 [1-400] and BRSK2 [1-400] were expressed in bacteria from pGEX vectors and purified as described previously $[10,38]$.

\section{Expression of LKB1 in HEK293 cells and activation of AMPK-related kinases in cell- free assays}

GST-LKB1 $1_{\mathrm{L}}$ or GST-LKB1 $1_{\mathrm{S}}$ with FLAG-STRAD $\alpha$ and myc-MO25 $\alpha$ were expressed in HEK293 cells and the complexes purified on glutathione-Sepharose as described previously [39]. GSTAMPK $\alpha 1$, GST-BRSK1 or GST-BRSK2 (1.5 $\mu \mathrm{g}$ in a final volume of $20 \mu \mathrm{l})$ were incubated with or without the indicated LKB1 complexes in Buffer A (50 mM Na Hepes, pH 7.4, $1 \mathrm{mM}$ DTT and $0.02 \%$ Brij-35) plus $5 \mathrm{mM} \mathrm{MgCl}{ }_{2}$ and $0.2 \mathrm{mM} \mathrm{ATP}$ for $15 \mathrm{~min}$ at $30^{\circ} \mathrm{C}$. For Western blotting analysis, the reaction was terminated by the addition of LDS sample buffer (Invitrogen). To determine kinase activities, $10 \mu \mathrm{l}$ was added to $15 \mu \mathrm{l}$ of mix to give final concentrations of $5 \mathrm{mM}$ $\mathrm{MgCl}_{2}, 200 \mu \mathrm{M}\left[\gamma_{-}{ }^{32} \mathrm{P}\right] \mathrm{ATP}(300 \mathrm{cpm} / \mathrm{pmol})$ and $200 \mu \mathrm{M}$ AMARA peptide [37] as substrate. After incubation for $15 \mathrm{~min}$ at $30^{\circ} \mathrm{C}$, incorporation of ${ }^{32} \mathrm{P}$-phosphate into the peptide substrate was determined as described previously [40].

\section{Preparation of germ cells from rat testis}

Germ cell suspensions were prepared from 26- and 31-old-Sprague-Dawley rats by collagenase digestion and Percoll purification by a modification of a previous method [41]. In 26-day-old rats, spermatocytes at all phases of the long meiotic prophase are present, and only rare tubules containing young spermatids are seen. In 31-day-old-rats, spermatids are the most prominent germ cell population present. Testes were decapsulated and digested with $0.1 \%$ collagenase (C0130 Sigma-Aldrich) and 0.006\% soybean trypsin inhibitor (T9003. Sigma-Aldrich) in Hanks' balanced salt solution (HBSS) for 5 min at room temp. The collagenase solution was diluted 4-fold with HBBS and seminiferous tubules allowed to sediment for $2 \mathrm{~min}$. The supernatant was discarded and the tubular pellet was washed twice with gentle shaking. Seminiferous tubules were cut into $2 \mathrm{~mm}$ segments and then digested with $0.05 \%$ collagenase, $0.003 \%$ soybean trypsin inhibitor and $0.003 \%$ deoxyribonuclease (DN25, Sigma-Aldrich) for $15 \mathrm{~min}$ at room temp, while carefully transferring the suspension from one tube to another with a pipette. The suspension was diluted with one vol 
HBSS and material allowed to sediment for $5 \mathrm{~min}$. The supernatant was transferred to a tube containing sufficient $2 \%$ bovine serum albumin (BSA) to make the final concentration $0.2 \%$ BSA. The suspension was allowed to settle for $10 \mathrm{~min}$. Germ cells remaining in suspension were collected by centrifugation at $400 \mathrm{xg}$ for $3 \mathrm{~min}$ at $4^{\circ} \mathrm{C}$. The resulting pellet was washed $2 \mathrm{x}$ with HBSS containing $0.2 \%$ BSA and $0.003 \%$ deoxyribonuclease. The final cell pellet was resuspended in a 1:1 mixture of Dulbecco's Modified Eagle's Medium-Ham's F-12 Medium with the addition of $15 \mathrm{mM}$ NaHCO3, $100 \mathrm{IU} / \mathrm{ml}$ penicillin, $2.5 \mathrm{mg} / \mathrm{ml}$ amphotericin B, $20 \mathrm{mM}$ Na Hepes, pH 7.4 (DMEM-F12) and seeded on a discontinuous four-layer $(20 \%, 25 \%, 32 \%, 37 \%)$ Percoll density gradient. The gradient was centrifuged at $800 \mathrm{xg}$ for $30 \mathrm{~min}$ at $4^{\circ} \mathrm{C}$. Two fractions were at the $32 \%-$ $37 \%$ interface and the $25 \%-32 \%$ interface were collected. To remove Percoll, 4 vols of DMEM-F12 were added and centrifugation at $400 \mathrm{xg}$ for $5 \mathrm{~min}$ at $4^{\circ} \mathrm{C}$ performed. Germ cells were resuspended in DMEM-F12 supplemented with $10 \mathrm{mg} / \mathrm{ml}$ transferrin, $5 \mathrm{mg} / \mathrm{ml}$ insulin, $5 \mathrm{mg} / \mathrm{ml}$ vitamin $\mathrm{E}$ and 4 $\mathrm{ng} / \mathrm{ml}$ hydrocortisone. Germ cell preparations were seeded at a density of $2 \times 10^{6} \mathrm{cell} / \mathrm{ml}$ in tissue culture flasks and cultured at $34^{\circ} \mathrm{C}$ in a mixture of $5 \% \mathrm{CO}_{2}: 95 \%$ air for $18 \mathrm{hr}$. During this initial period, the few Sertoli cells contaminating the germ cell preparation attached to the plastic surface. Purified germ cells were obtained by carefully removing the medium and centrifuging at $400 \mathrm{xg}$ for $5 \mathrm{~min}$ at $4^{\circ} \mathrm{C}$. For Western blot analysis, cells were resuspended on ice with $70 \mathrm{ml}$ PBS containing $0.7 \mathrm{ml}$ (per $1 \times 10^{6}$ cells) protease inhibitor cocktail (P8340, Sigma-Aidrich), $2 \mathrm{mM} \mathrm{PMSF}, 1 \mathrm{mM}$ EGTA, $1 \mathrm{mM}$ EDTA and $1 \mathrm{mM} \mathrm{NaF}$, and disrupted by ultrasonic irradiation. To measure the DNA content, cells were resuspended in DMEM:F12 supplemented with 50\% fetal bovine serum and fixed in ice-cold $70 \%$ ethanol. Propidium iodide was added to fixed cells to a final concentration of $50 \mathrm{mg} / \mathrm{ml}$. Flow cytometry was performed using a FACS Caliber (Becton Dickinson).

\section{Isolation of Leydig cells}

Testes from adult Sprague-Dawley rats were removed and placed in ice-cold PBS, pH 7.4, containing $0.1 \%$ BSA. Leydig cells were isolated by a modification of a previous method [42]. Testes were decapsulated and digested with a solution of $0.025 \%$ collagenase (C0130, SigmaAldrich) and $0.001 \%$ soybean trypsin inhibitor in Medium 199 containing 0.1\% BSA (M199-BSA) under constant agitation at $34^{\circ} \mathrm{C}$ for $15 \mathrm{~min}$. The suspension was diluted $4 \mathrm{x}$ with cold M199-BSA. Seminiferous tubules were allowed to sediment and the supernatant recovered. Seminiferous tubules were washed 2x with M199-BSA and supernatants obtained after sedimentation combined with the first supernatant. Interstitial cells were collected by centrifugation at $100 \mathrm{xg}$ for $15 \mathrm{~min}$ at $4^{\circ} \mathrm{C}$. Cells were resuspended in DMEM-F12. Leydig cells were purified using a discontinuous fourlayer $(21 \%, 26 \%, 40 \%, 60 \%)$ Percoll gradient. The gradient was centrifuged at $800 \mathrm{xg}$ for $30 \mathrm{~min}$ at $4^{\circ} \mathrm{C}$. The interface between 40 and $60 \%$ Percoll was collected, 4 vols of DMEM-F12 added, and centrifugation at $400 \mathrm{xg}$ for $5 \mathrm{~min}$ at $4^{\circ} \mathrm{C}$ was performed. The cell pellets were resuspended on ice with $70 \mathrm{ml}$ PBS containing $0.7 \mathrm{ml}$ (per $1 \times 10^{6}$ cells) protease inhibitor cocktail, $2 \mathrm{mM}$ PMSF, $1 \mathrm{mM}$ EGTA, $1 \mathrm{mM}$ EDTA and $1 \mathrm{mM} \mathrm{NaF}$ and disrupted by ultrasonic irradiation.

\section{Isolation of Sertoli cells}

Sertoli cells were isolated from 20-day-old Sprague-Dawley rats essentially as previously described [43]. Testes were decapsulated and digested with $0.1 \%$ collagenase (C0130, Sigma-Aldrich) and $0.006 \%$ soybean trypsin inhibitor in HBSS for $5 \mathrm{~min}$ at room temp. Seminiferous tubules were allowed to sediment, washed $2 \mathrm{x}$ with HBSS, cut into $2 \mathrm{~mm}$ segments and submitted to treatment with $1 \mathrm{M}$ glycine-2 mM EDTA, $0.003 \%$ deoxyribonuclease, $\mathrm{pH} 7.4$, for $10 \mathrm{~min}$ at room temp to remove peritubular cells. Next, 9 vols of HBSS were added, and seminiferous tubules were allowed 
to sediment for $30 \mathrm{~min}$ at room temp. The pellet was recovered and digested again with collagenase under identical conditions for 10 min while carefully transferring the suspension from one tube to another with a pipette. After this, 2 vols of HBSS were added and Sertoli cell aggregates were collected by centrifugation at $400 \mathrm{xg}$ at $4^{\circ} \mathrm{C}$ for $3 \mathrm{~min}$. The pellet obtained was resuspended in HBSS and submitted to sedimentation for $10 \mathrm{~min}$ at unit gravity (contaminating germ cells remain in suspension, while Sertoli cell aggregates are recovered in the sediment). The supernatant was discarded and the sediment was washed 1x with DMEM-F12, collected by centrifugation at $400 \mathrm{xg}$ at $4^{\circ} \mathrm{C}$ for $3 \mathrm{~min}$, and finally resuspended in DMEM-F12 supplemented with $10 \mathrm{mg} / \mathrm{ml}$ transferrin, 5 $\mathrm{mg} / \mathrm{ml}$ insulin, $5 \mathrm{mg} / \mathrm{ml}$ vitamin E and $4 \mathrm{ng} / \mathrm{ml}$ hydrocortisone. Sertoli cells were seeded in a culture dish $\left(60 \mathrm{mg}\right.$ DNA $\left./ 10 \mathrm{~cm}^{2}\right)$ and cultured at $34^{\circ} \mathrm{C}$ in a mixture of $5 \% \mathrm{CO} 2: 95 \%$ air. The medium was changed after $48 \mathrm{hr}$ and cells collected on day 4, when the purity of Sertoli cells reached $90 \%$ as judged by phase contrast microscopy. Remaining cell contaminants were of germ cell origin. The Sertoli cells were washed once with PBS, collected on ice with $100 \mathrm{ml}$ PBS containing $1 \mathrm{ml}$ protease inhibitor cocktail, $2 \mathrm{mM}$ PMSF, $1 \mathrm{mM}$ EGTA, $1 \mathrm{mM}$ EDTA and $1 \mathrm{mM} \mathrm{NaF}$, and disrupted by ultrasonic irradiation.

\section{Histology of testis and epididymis from $\mathrm{LKB}^{+/+}$and $\angle K B 1^{\text {fl/fl }}$ mice}

$\mathrm{LKB}^{+/+}$and $\mathrm{LKB} 1^{\mathrm{fl} / \mathrm{fl}}$ mice were obtained by breeding and genotyping as described previously [44]. Testes and epididymal tissue were dissected out and fixed in $10 \%$ neutral buffered formalin overnight. Tissues were embedded in paraffin and sectioned for standard Haematoxylin and Eosin staining. Slides were viewed on a Zeiss light microscope, and images taken using a Zeiss Axiocam and processed with AxioVision software.

\section{Sperm counts and assays of sperm motility}

Spermatozoa were prepared for counting and motility analysis by macerating the epididymis from $\mathrm{LKB}^{+/+}$and LKB1 ${ }^{\mathrm{fl} / \mathrm{fl}}$ mice in $200 \mu \mathrm{l}$ of G-IVF ${ }^{\mathrm{TM}}$ PLUS buffer (Vitrolife, Sweden). Tissue was pipetted up and down once or twice, the large tissue fragments allowed to settle and samples of the upper suspension transferred into a clean Eppendorf tube and maintained at $37^{\circ} \mathrm{C}$ prior to counting and motility assays. For sperm counts, the sample was diluted 1:5 in water, aliquots $(10 \mu \mathrm{l})$ pipetted onto an improved Neubauer haemocytometer, and the number of sperm counted using an Olympus IX17 microscope. For motility measurements, $4 \mu \mathrm{l}$ of the undiluted sample was placed on a glass slide and motility assessed using a computer-aided semen analyser (Hamilton Thorne CEROS) according to manufacturer's instructions.

\section{Microscopic analysis of spermatozoa from LKB1 $1^{+/+}$and LKB1 ${ }^{\text {fl/fl }}$ mice}

Spermatozoa were prepared for imaging by finely chopping the epididymis in $4 \%$ paraformaldehyde, which was transferred into a microcentrifuge tube and centrifuged $(3,000 \mathrm{rpm}, 2$ $\left.\min , 4^{\circ} \mathrm{C}\right)$. The supernatant containing spermatozoa was spotted onto a slide with a drop of Vectashield mounting medium containing 4',6-diamidino-2-phenylindole (DAPI, Vector Labs Inc, California) and a coverslip sealed on top. Images were taken using the bright field and DAPI filter of a Deltavision microscope. Images were also taken using a Nikon Coolpix 4500 digital camera attached to a Zeiss light microscope; sperm counts were taken from these images.

For scanning EM the epididymis was finely chopped in Peters fixative (1.25\% glutaraldehyde, $1 \%$ paraformaldehyde, $80 \mathrm{mM}$ Na cacodylate $\mathrm{pH} 7.2,0.02 \% \mathrm{CaCl}_{2}$ ) and left in fixative overnight. Spermatozoa were collected on $1 \mu \mathrm{m}$ Shandon Nucleopore membrane filters. After rinsing the membranes $2 \times 15 \mathrm{~min}$, with $80 \mathrm{mM} \mathrm{Na}$ cacodylate $\mathrm{pH} 7.2$, samples were post-fixed with $0.2 \% \mathrm{OsO}_{4}$ 
in water overnight. Membranes were washed 2x15 min in water and then dehydrated through a graded ethanol series. Samples were critically point dried using a BAL-Tec CPD D30, mounted on aluminium stubs using adhesive tabs, and coated with $20 \mathrm{~nm} \mathrm{Au} / \mathrm{Pd}$ using a Cressington 208HR sputter coater. Specimens were examined in a Philips XL30 ESEM operating at an accelerating voltage of $15 \mathrm{Kv}$, and images recorded using SIS XL DOCU imaging software.

\section{Western blotting and other analytical procedures}

SDS-PAGE used precast Bis-Tris 4-12\% gradient polyacrylamide gels in the MOPS buffer system (Invitrogen). Proteins were transferred to nitrocellulose membranes (BioRad) using the Xcell II Blot Module (Invitrogen). Membranes were blocked for $1 \mathrm{hr}$ in Tris-buffered saline (TBS) containing $5 \%(\mathrm{w} / \mathrm{v})$ skimmed milk. The membranes were probed with appropriate antibody $(0.1-1 \mu \mathrm{g} / \mathrm{ml})$ in TBS-Tween, $2 \%(\mathrm{w} / \mathrm{v})$ skimmed milk. Detection was performed using secondary antibody (1 $\mu \mathrm{g} / \mathrm{ml}$ ) coupled to IR 680 or IR 800 dye, and the membranes were scanned using the Li-Cor Odyssey IR imager. Protein concentrations were determined by Coomassie Blue binding [45] with bovine serum albumin as standard.

\section{RESULTS}

\section{Analysis of mRNAs encoding LKB1 by database searching}

We previously reported that, during purification from rat liver, two forms of the LKB1:STRAD:MO25 complex could be resolved by anion exchange chromatography, which contained forms of the LKB1 polypeptide with differing mobilities on SDS-PAGE [7]. Since there is a single gene encoding LKB1, we suspected that the two forms might arise by alternative splicing of the mRNA. Using the amino acid sequences for human (Q15831), mouse (Q9WTK7) and rat (XP_234900) LKB1, we searched the respective genome databases and located the sequences on chromosomes 19, 10 and 7 respectively. Each amino acid sequence was aligned against the genomic sequence and intron/exon boundaries identified. We then searched for and aligned expressed sequence tags (ESTs) with the genomic sequences. A summary of the alignment is shown in Fig. 1A; the full alignment is available from the authors on request. Interestingly, in all three species a non-canonical splice site is used for exon 2. A canonical site does exist, and was used in one incorrect prediction for the amino acid sequence of rat LKB1 (XP_234900.1), but every EST found utilizes the non-canonical splice site, in all three species.

Our analysis suggested that there are two forms of $L K B 1$ mRNA caused by alternative splicing after exon 8 . These would give rise to two versions of the protein, designated $L K B 1_{S}$ and $L K B 1_{L}$ for the short and long forms respectively, which have different $\mathrm{C}$-terminal sequences encoded by exons 9A and 9B. The $L K B 1_{L}$ mRNA also has an additional exon (exon 10) that encodes 3'untranslated sequence only. We also noted the use of alternate polyadenylation sites in exon 10 in both human and mouse. ESTs corresponding to LKB1 $1_{\mathrm{S}}$ were particularly common in libraries derived from rat testis. In the rat, $\mathrm{LKB} 1_{\mathrm{S}}$ is predicted to be a protein of 412 residues with a mass of $46.5 \mathrm{kDa}$, while $\mathrm{LKB} 1_{\mathrm{L}}$ is predicted to be a protein of 436 amino acids with a mass of $49.2 \mathrm{kDa}$. The first 373 residues encoded by exons 1 to 8 (MDVA...TVPG), including the kinase domain (44309), would be identical in both forms. $\mathrm{LKB} 1_{\mathrm{S}}$ would then have a unique, 39 residue sequence (VEET...GAVV) at the C-terminus encoded by exon 9A, whereas LKB1 $1_{\mathrm{L}}$ would have a unique 63 residue sequence (QVLE...CKQQ, including the Ser-431 phosphorylation site and the cysteine residue in the C-terminal-CAAX sequence that forms the farnesylation site) encoded by exon $9 \mathrm{~B}$. 
Alignments of the predicted amino acid sequences of the unique $\mathrm{C}$-terminal regions of $\mathrm{LKB} 1_{\mathrm{S}}$ and $\mathrm{LKB} 1_{\mathrm{L}}$, encoded by exons $9 \mathrm{~A}$ and $9 \mathrm{~B}$ respectively, are shown in Fig. $1 \mathrm{~B}$. The unique region of the long form is more highly conserved, being $70 \%$ identical between mouse and human, as opposed to only $36 \%$ identity for the unique region of the short form.

\section{Analysis of LKB1 mRNAs by 3'-RACE}

To confirm the existence of two forms of $L K B 1 \mathrm{mRNA}$, we carried out 3'-RACE (Rapid Amplification of cDNA Ends) using cDNA from rat testis as the template, and a forward primer (encoding residues 161-168) derived from the common region. This generated a major product of about $830 \mathrm{bp}$ and a minor product of about $560 \mathrm{bp}$ (not shown). Sequencing of the $830 \mathrm{bp}$ product yielded a sequence encoding residues 330-412 of $\mathrm{LKB} 1_{\mathrm{S}}$, covering exons 8 and $9 \mathrm{~A}$ and extending right to the $\mathrm{C}$-terminus of the protein, followed by a TAG stop codon. Sequencing of the $560 \mathrm{bp}$ product yielded a sequence encoding residues 291-406 of LKB1 $1_{\mathrm{L}}$ including about half of the unique $\mathrm{C}$-terminal region. Thus, we could distinguish two distinct mRNAs in rat testis mRNA corresponding to $\mathrm{LKB} 1_{\mathrm{S}}$ and $\mathrm{LKB} 1_{\mathrm{L}}$.

\section{Analysis of LKB1s and LKB1 $L$ by tryptic peptide mass fingerprinting}

To confirm the structural differences between the $L K B 1_{L}$ and $L K B 1_{S}$ at the protein level, we partially purified LKB1 complexes from rat testis and immunoprecipitated them using an antibody (anti-LKB1(N)) raised against an epitope (residues 25-36) from the common N-terminal region. SDS-PAGE analysis of the immunoprecipitate revealed five major polypeptides (labelled P1 to P5 in order of increasing mobility, Fig. 2A), which had estimated masses by comparison with marker proteins of 50, 46, 43, 40 and $36 \mathrm{kDa}$. All five were analyzed by matrix-assisted laser desorption ionization time-of-flight (MALDITOF) mass spectrometry of tryptic peptides. Using this method, P5 was identified as MO25 $\alpha$, and P3 and P4 as STRAD $\alpha$, which has previously been observed to migrate as two or three distinct polypeptides when purified from rat liver [7]. There are two versions of rat STRAD $\alpha$ in the NCBI database, i.e. AH81911.1 (GI:51858665), which is predicted to have 373 residues and a mass of $41.4 \mathrm{kDa}$, and NP_877972.1 (GI:33414519), which is predicted to have 393 residues (including an N-terminal extension not present in AH81911.1) and a mass of $43.5 \mathrm{kDa}$. P3 and P4 may correspond to these, although we were unable to identify any peptides from the unique N-terminal region of NP_877972.1 in P3.

P1 and P2 were both identified as LKB1. Fig. 2B shows the complete amino acid sequences of rat $L K B 1_{S}$ and $L K B 1_{L}$ derived from our analysis of DNA sequences in the databases. Tryptic peptides for which we obtained a matching mass in P1 and P2 are indicated by boxes. We identified 17 peptides of the same mass in P1 and P2, accounting for 246 out of 373 residues (64\%) in the Nterminal region common to both variants. In P1 we also identified a peptide of 4949.3 Da, corresponding to residues 348-391 that straddle the junction between exons 8 and 9B, and one of 1504.7 Da, corresponding to residues 392-405 immediately C-terminal to that. Both of these peptides were absent from the digest of P2. Conversely, in P2 we identified a peptide of 1829.9 Da, corresponding to residues 394-412 of the XP_234900.2 sequence, which is the C-terminal peptide of the protein; this peptide was not detected in the digest of P1.

\section{Analysis of LKB1s and LKB1 $1_{\mathrm{L}}$ by Western blotting}

To study the tissue distribution of LKB1 isoforms at the protein level, we analyzed the expression of $\mathrm{LKB} 1_{\mathrm{S}}$ and $\mathrm{LKB} 1_{\mathrm{L}}$ in extracts of rat, mouse and human tissues by Western blotting using three different anti-peptide antibodies, i.e. anti-LKB1(N), which recognizes a common N- 
terminal epitope, and anti-LKB1 $1_{\mathrm{S}}$ and anti-LKB1 $1_{\mathrm{L}}$, the latter two raised against $\mathrm{C}$-terminal epitopes that were unique to each variant. To enhance the signals obtained, for rat and mouse extracts we first immunoprecipitated with a fourth antibody made against full-length recombinant $L K B 1_{L}$. Fig. $3 \mathrm{~A}$ shows results obtained using rat tissues. If we loaded samples derived from immunoprecipitation of $20 \mu \mathrm{g}$ of extract protein into each lane, LKB1 polypeptides were only clearly visible in extracts of brain (Br) and testis (Te). The brain sample exhibited just the upper band of $50 \mathrm{kDa}$ recognized by the anti-LKB1(N) and anti-LKB1 $1_{\mathrm{L}}$ antibodies, while in the testis polypeptides of $50 \mathrm{kDa}$ (recognized by the anti-LKB1(N) and anti-LKB1 $1_{\mathrm{L}}$ antibodies) and $46 \mathrm{kDa}$ (recognized by the anti-LKB1(N) and anti-LKB1 $1_{\mathrm{S}}$ antibodies) were evident. As assessed by the signal obtained using anti-LKB1(N), $\mathrm{LKB} 1_{\mathrm{S}}$ is more abundant than $\mathrm{LKB} 1_{\mathrm{L}}$ in testis, although in a sample of partially purified rat testis $\mathrm{LKB} 1$ run as a marker $(\mathrm{RT})$, the $\mathrm{LKB} 1_{\mathrm{L}}$ and $\mathrm{LKB} 1_{\mathrm{S}}$ polypeptides were of equal intensity.

To examine the expression of the isoforms in other tissues, we ran the Western blots again with the amount of protein increased 10-fold for all tissues except brain and testis. This revealed that both forms were detectable in all tissues examined. Although the signals were very faint for liver (Li) and kidney (Ki), both forms are present in the former because we previously purified them from rat liver [7]). As assessed by the signal obtained using anti-LKB $1(\mathrm{~N}), \mathrm{LKB} 1_{\mathrm{L}}$ is more abundant than $\mathrm{LKB}_{\mathrm{S}}$ in brain $(\mathrm{Br})$, heart $(\mathrm{He})$, skeletal muscle $(\mathrm{Mu})$, liver $(\mathrm{Li})$, kidney (Ki), lung $(\mathrm{Lu})$ and pancreas $(\mathrm{Pa})$, whereas the opposite is true in testis $(\mathrm{Te})$ and spleen $(\mathrm{Sp})$. Using the antiLKB1 $1_{\mathrm{S}}$ antibody, we also detected an additional polypeptide of intermediate size (labelled "??" in Fig. 3A), especially in brain and heart. On close inspection, this could also be seen in the antiLKB1(N) blots migrating just ahead of $\mathrm{LKB} 1_{\mathrm{L}}$, but not in the anti-LKB1 $1_{\mathrm{L}}$ blots. Since this polypeptide was immunoprecipitated using the antibody against full-length LKB1 and is recognized by both anti-LKB1(N) and anti-LKB1 $1_{\mathrm{S}}$ on Western blots, we suspect that it may represent yet another variant containing the exon $9 \mathrm{~A}$ sequence. However, we were unable to obtain enough material to confirm this by mass spectrometry.

Fig. 3B shows Western blotting of immunoprecipitates of mouse tissue extracts analyzed in the same way. Although we did not analyze lung and pancreas, the results were very similar to those obtained with rat extracts, including the putative third variant running between $\mathrm{LKB} 1_{\mathrm{L}}$ and $\mathrm{LKB} 1_{\mathrm{S}}$ in brain and heart. Fig. 3C shows Western blots of extracts of human brain, heart, liver and testis probed with anti-LKB1(N) and anti-LKB $\mathrm{L}_{\mathrm{L}}$, with purified rat testis enzyme $(\mathrm{RT})$ run as a positive control. Because the extracts were obtained already dissolved in SDS, for the human samples we could not perform prior immunoprecipitation. However, the $\mathrm{LKB} 1_{\mathrm{L}}$ polypeptide was clearly visible in the brain extract, whereas both $\mathrm{LKB} 1_{\mathrm{L}}$ and $\mathrm{LKB} 1_{\mathrm{S}}$ were visible in testis, with $\mathrm{LKB} 1_{\mathrm{S}}$ being more abundant as in rodents. Probably because the peptide epitope against which the $\mathrm{LKB} 1_{\mathrm{S}}$ antibody was made is poorly conserved in humans (Fig. 1B), our anti-LKB $1_{\mathrm{S}}$ antibody did not recognize human LKB1 $1_{\mathrm{S}}$ (not shown).

To confirm that $L K B 1_{S}$, like $L K B 1_{L}$, formed a complex with STRAD and MO25 in testis, we made rat testis extracts and immunoprecipitated with anti-LKB $1_{\mathrm{L}}$, anti-LKB $1_{\mathrm{S}}$, or with a control sheep immunoglobulin. The extract and each immunoprecipitate were then analyzed by Western blotting using antibodies against STRAD $\alpha$ and MO25 $\alpha$. The results (Fig. 3D) confirmed that both $\mathrm{LKB} 1_{\mathrm{L}}$ and $\mathrm{LKB} 1_{\mathrm{S}}$ formed complexes with STRAD $\alpha$ and MO25 $\alpha$ in testis. Two polypeptides of 43 and $40 \mathrm{kDa}$ were observed for STRAD $\alpha$ as in Fig. 2. Although the STRAD and MO25 polypeptides were only faintly detected in the anti-LKB1 $1_{\mathrm{L}}$ blots due to the low expression of this variant in testis, we have previously shown that $\mathrm{LKB}_{\mathrm{L}}$ associates with STRAD $\alpha$ and $\mathrm{MO} 25 \alpha$ in rat liver [7]. 


\section{Subcellular localization of LKB1s and LKB1}

Since $\mathrm{LKB} 1_{\mathrm{S}}$ lacks the C-terminal -CKQQ sequence providing the cysteine that is farnesylated on $\mathrm{LKB} 1_{\mathrm{L}}$ [31], we wondered whether the two isoforms might have different subcellular localizations. However, after expression of $\mathrm{LKB} 1_{\mathrm{L}}$ or $\mathrm{LKB} 1_{\mathrm{S}}$ with or without STRAD $\alpha$ and MO25 $\alpha$ in HeLa cells, with detection by indirect immunofluorescence using isoform-specific antibodies, or by Western blotting after separation of extracts into soluble and membrane fractions, we could obtain no evidence that this was the case. These data are presented in a supplementary file (Fig. S1).

\section{LKB1s and LKB1 L activate AMPK and AMPK-related kinases}

To determine whether both variants of LKB1 are capable of activating AMPK and the AMPKrelated kinases (ARKs) in intact cells, we co-expressed $L K B 1_{L}$ or $L K B 1_{S}$ with FLAG-STRAD $\alpha$ and myc-MO25 $\alpha$ in HeLa cells and measured the phosphorylation and activity of endogenous kinases compared with untransfected controls. By probing blots with the anti-LKB1(N) antibody, the expression of $\mathrm{LKB} 1_{\mathrm{L}}$ was higher than that of $\mathrm{LKB} 1_{\mathrm{S}}$ in these cells (Fig. 4A). Despite this, endogenous AMPK was activated and phosphorylated to approximately equal extents compared with control cells treated with empty vector (Fig. 4B). Similar results were obtained with SIK1 (SIK), SIK2 (QIK), SIK3 (QSK) and NUAK2 (SNARK): in these cases the basal activity in control cells was very low and there was a large increase on expression of either splice variant (Fig. 4C4F).

As the brain specific kinases BRSK1 and BRSK2 (also known as SAD-B and SAD-A) are not expressed in HeLa cells, we used a different approach to assess their phosphorylation and activation by $L K B 1_{L}$ and $L K B 1_{S}$ complexes. We co-expressed GST-tagged $L K B 1_{L}$ or $L K B 1_{S}$ in HEK-293 cells with FLAG-STRAD- $\alpha$ and myc-MO25 $\alpha$ and purified the recombinant complexes using glutathione-Sepharose chromatography. Fig. 5A shows analysis of the purified complexes by blotting with anti-GST, -FLAG and -myc antibodies. This shows that the LKB1:STRAD $2: M O 25 \alpha$ complex was highly enriched in the glutathione-Sepharose eluate. The bottom panel of Fig. 5A shows a Western blot probed with anti-GST using a lighter loading of the purified complex, revealing that the content of $\mathrm{LKB} 1_{\mathrm{L}}$ and $\mathrm{LKB} 1_{\mathrm{S}}$ in the two preparations was equivalent.

As an initial test of this method, we examined the ability of the purified $\mathrm{LKB} 1_{\mathrm{L}}$ and $\mathrm{LKB} 1_{\mathrm{S}}$ complexes to phosphorylate and activate a GST fusion of the kinase domain from rat AMPK- $\alpha 1$. Both complexes were active, but the LKB1 $1_{\mathrm{S}}$ complex appeared to activate the $\alpha 1$ kinase domain, and phosphorylate Thr-172, more effectively than the LKB1 $1_{\mathrm{L}}$ complex (Fig. 5B, 5C). Similar results were obtained with GST-BRSK1 and GST-BRSK2, although there were quantitative differences, with the LKB1 $1_{\mathrm{S}}$ complex appearing to phosphorylate and activate BRSK2 much more efficiently than the LKB1 $1_{\mathrm{L}}$ complex (Fig. 5E, 5G), while this difference was less marked with BRSK1 (Fig. $5 \mathrm{D}, 5 \mathrm{~F})$.

\section{A role for LKB1s in spermiogenesis}

We used a mouse with a "floxed" $L k b 1$ gene to investigate the function of $\mathrm{LKB} 1_{\mathrm{s}}$. This mouse carries an allele of $L k b l$ in which exons 4 to 8 have been replaced by a cDNA-IRES NEO-loxP(3') cassette; the cDNA encodes exons 5, 6, 7, 8 and $9 \mathrm{~b}$ of $\mathrm{Lkb}_{\mathrm{L}}$ [44]. Although the genome of these mice still contains the exon 9a sequence, this was not likely to be transcribed as part of the $L k b 1$ transcript because the cDNA cassette is already spliced and carries polyadenylation sequences. Therefore, these homozygous floxed mice $\left(L k b l^{f l f f l}\right)$ should represent a de facto knockout of Lkb1 $1_{\mathrm{s}}$. To confirm this at the mRNA level, we extracted RNA from rat testis and used it as a template for 
RT-PCR using forward primers from the region common to $L k b 1_{L}$ and $L k b 1_{S}$ and reverse primers from their unique $3^{\prime}$ regions (expected size of products 592 and $609 \mathrm{bp}$ respectively). We also used primers to amplify $18 \mathrm{~S}$ rRNA as a positive control. The results (Fig. 6A) showed that mRNA encoding $\mathrm{Lkb}_{\mathrm{S}}$ was completely absent in the RNA from the homozygous floxed mice, which still contained both $\mathrm{Lkb}_{\mathrm{L}}$ mRNA and $18 \mathrm{~S}$ rRNA. To confirm the absence of $\mathrm{Lkb} 1_{\mathrm{S}}$ in the homozygous floxed mice at the protein level, we also carried out Western blotting with increasing amounts of testis protein (Fig. 6B).

The $L k b I^{f l f l}$ mice have no overt phenotype, other than that the male mice are sterile [44]. Our current findings that $\mathrm{Lkb}_{\mathrm{S}}$ is expressed at highest levels in the testis, and is absent in the testis of the $L k b l^{f l f l}$ males, suggests that this variant might play a crucial role in spermatogenesis. We first looked at the expression of $\mathrm{Lkb}_{\mathrm{S}}$ and $\mathrm{Lkb} 1_{\mathrm{L}}$ in different regions of the male reproductive system in wild type mice. Expression of $\mathrm{Lkb} 1_{\mathrm{S}}$, measured either using the antibody specific for that variant (anti-LKB1 $1_{\mathrm{S}}$ ) or the antibody that recognizes both variants (anti-LKB1(N)) was very high in the testis but much lower in the epididymis and in spermatozoa derived from epididymis (Fig. 6C). By contrast, $\mathrm{Lkb} 1_{\mathrm{L}}$ appeared to be expressed at low levels in all three preparations. This suggested that $\mathrm{Lkb}_{\mathrm{S}}$ might have a function in developing, rather than in mature, spermatozoa.

We next examined the expression of $\mathrm{LKB}_{\mathrm{S}}$ in testis from rats of different ages (Fig. 6D). LKB1 $1_{S}$ expression was absent in testis from rats that were 20,23 and 27 days old, but was evident in 30 day rats and much stronger in 60 day rats. The expression of LKB1 therefore corresponds to the time (day 27) when haploid spermatids begin to appear. We also examined expression in Leydig cells (LC), Sertoli cells (SC) and three different preparations of germ cells (G1, G2, G3) made by collagenase digestion and Percoll gradient centrifugation of rat testis (Fig. 6E). LKB1 $1_{\mathrm{S}}$ was clearly expressed in whole testis, with the expression being greater in 60 day rather than 30 day rats as before. It was expressed in germ cells but not in Leydig or Sertoli cells. However, expression varied markedly in the three different preparations of germ cells. Preparation G1 was from 26-day old rats (32-37\% Percoll interface), contained 75\% tetraploid cells and 6\% haploid cells and expressed no detectable $\mathrm{LKB} 1_{\mathrm{S}}$. Preparation G2 was from 26-day old rats (25-32\% Percoll interface), contained $73 \%$ tetraploid cells and $16 \%$ haploid cells and expressed low levels of LKB1 $1_{s}$. Preparation G3 was from 31-day old rats, contained $27 \%$ tetraploid cells and $63 \%$ haploid cells and expressed high levels of $\mathrm{LKB} 1_{\mathrm{s}}$. Thus, the highest expression of $\mathrm{LKB} 1_{\mathrm{S}}$ appears to be in developing germ cells after meiosis. All three germ cell preparations contained small proportions of diploid cells (10-20\%) that may represent contamination with somatic cells.

We also analyzed the testis and epididymis, and the spermatozoa stored in the latter, from the mice that lacked $\mathrm{Lkb}_{\mathrm{S}}$ and their wild type littermates. Histological analyses using haematoxylin and eosin staining of testis sections did not reveal any marked differences (data not shown), but there were obvious differences in the epididymis. Whereas the caudal region (where mature spermatozoa are stored) was distended and packed with spermatozoa in the wild type, it appeared to be shrunken and almost empty in the $L k b l^{f l f l}$ mice (Fig. 7). To recover the spermatozoa we finely chopped the whole epididymis, resuspended in buffer used for motility analysis of human spermatozoa, allowed the large tissue fragments to settle, and counted spermatozoa. This revealed that the number of mature spermatozoa was drastically reduced in the $L k b l^{f l f l}$ mice. In six $L k b l^{f l f l}$ mice of ages ranging from 2 to 12 months, the sperm count was reduced by $98.6 \pm 1.0 \%$ compared with their wild type littermates. Analysis of motility revealed that the spermatozoa from the wild type littermates had normal motility ( $\approx 67 \%$ motile with $28 \%$ progressive), but that the few spermatozoa from the $L k b l^{f l f l}$ mice were completely non-motile. In addition, the few spermatozoa 
that were recovered from the knockout mice had an abnormal morphology. Viewed by differential bright field microscopy or by scanning electron microscopy, the sperm heads from the wild type littermates had the characteristic hooked shape caused by the prominent acrosome in mouse spermatozoa. However, the sperm heads from the $L k b l^{f l f l}$ mice were invariably rounded and showed no evidence of the hooked acrosome. In addition, the chromatin appeared to be less highly condensed than in wild type sperm heads as judged by staining of DNA in fluorescence microscopy (Fig. 7).

\section{Discussion}

The first indication that LKB1 might exist as two protein variants came from studies showing that the LKB1 complex could be separated into two fractions during purification from rat liver [7]. When we searched cDNA databases from rat, mouse and human, we found sequences corresponding to two distinct forms of LKB1 mRNA (Fig. 1A) with many of the cDNAs corresponding to the short form (particularly in the case of the rat) being derived from the testis. This is consistent with our findings that mRNAs encoding two distinct forms of LKB1 could be cloned by a 3'-RACE procedure from rat testis cDNA and could also be detected by RT-PCR (Fig. 6A). To confirm expression of both variants at the protein level, we partially purified LKB1 from rat testis extracts and immunoprecipitated using an antibody that recognizes both forms. This resulted in the identification by peptide mass fingerprinting of $\mathrm{LKB} 1_{\mathrm{L}}, \mathrm{LKB} 1_{\mathrm{S}}, \mathrm{MO} 25 \alpha$ and two forms of STRAD $\alpha$. Thus, the existence of the two splice variants of LKB1 was demonstrated unequivocally at the protein level in rat testis.

We next examined the tissue distribution of the two splice variants in rat, mouse and human extracts using an antibody raised against an $\mathrm{N}$-terminal epitope expected to recognize both forms (anti-LKB1(N)) and two antibodies raised against unique sequences encoded by exons 9B (anti$\mathrm{LKB} 1_{\mathrm{L}}$ ) and $9 \mathrm{~A}\left(\right.$ anti-LKB1 $1_{\mathrm{S}}$ ). In most tissue extracts, $\mathrm{LKB} 1_{\mathrm{L}}$ was the predominant form, although $\mathrm{LKB} 1_{\mathrm{S}}$ was always detectable if sufficient protein was loaded onto the gel. The exceptions to this were spleen extracts from rats and mice (a human spleen sample was not available) and testis extracts from all three species, where $\mathrm{LKB} 1_{\mathrm{S}}$ was the predominant form. $\mathrm{LKB} 1_{\mathrm{S}}$ was much more abundant in testis than any other tissue extract, whereas $L K B 1_{L}$ was most abundant in brain extracts.

We next considered the possibility that the unique C-terminal regions of $\mathrm{LKB} 1_{\mathrm{L}}$ and $\mathrm{LKB} 1_{\mathrm{S}}$ might provide docking sites such that they would differ in their specificity for the downstream protein kinases. To test this, we co-expressed $\mathrm{LKB} 1_{\mathrm{L}}$ and $\mathrm{LKB} 1_{\mathrm{S}}$ in HeLa cells, which do not express endogenous LKB1, with FLAG-STRAD $\alpha$ and $m y c-M O 25 \alpha$ and assessed the activation state of AMPK and AMPK-related kinases (SIK1, SIK2, SIK3 and NUAK2/SNARK). We also studied the activation of AMPK, BRSK1/SAD-B and BRSK2/SAD-A by recombinant $L K B 1_{\mathrm{L}}$ and $\mathrm{LKB} 1_{\mathrm{S}}$ complexes in cell free assays. Our results did not support the idea that the two splice variants have intrinsic specificity for any of the downstream targets.

Recently, a conditional mouse model of the $L k b 1$ gene has been generated [44, 46]. Although exon 9A is still present in the genome of $L k b 1^{f l l f l}$ mice, it can no longer be transcribed as part of the Lkb1 mRNA, abrogating production of the LKB1 $1_{\mathrm{S}}$ variant. This was confirmed in the present study both by RT-PCR and by Western blotting (Fig. 6). These mice do not have an obvious developmental phenotype, other than the sterility of the $L k b I^{f l l f l}$ male mice. In wild type mice, we found that expression of $\mathrm{Lkb}_{\mathrm{S}}$ was particularly high in the testis where spermatozoa are developing, and then dropped markedly in the epididymis (where mature spermatozoa are stored) as 
well as in the mature spermatozoa themselves. By contrast, the expression of $L k b 1_{L}$ was low and uniform in all stages (Fig. 6C). Analysis by Western blotting of different cell types prepared from rat testis showed that $\mathrm{LKB} 1_{\mathrm{S}}$ was expressed at high levels in germ cells but not in Leydig or Sertoli cells. Moreover, in different preparations of germ cells, $\mathrm{LKB} 1_{\mathrm{S}}$ expression was much higher in those that had a high proportion of cells with haploid (1n) DNA content and a low proportion of tetraploid (4n) DNA content. These haploid cells represent early, round spermatids and have not yet undergone the dramatic changes in cell polarity that occur during spermiogenesis, including the formation of the acrosome body at the sperm head, growth of the sperm tail, the formation of the mid-piece containing mitochondria, and the compaction of chromatin.

The most striking differences between the $L k b 1^{f l f l}$ mice (which are Lkb1 $1_{\mathrm{S}}$ knockouts) and their wild type littermates were in the epididymis, and particularly in the caudal (tail) region where mature spermatozoa are stored. While the tubule in the caudal region of the wild type was distended and packed with spermatozoa, in the knockouts the tubule was shrunken and appeared to be almost empty. Consistent with this, the numbers of spermatozoa that we could recover from the epididymis, in mice ranging from 2 to 12 months, were reduced by $>98 \%$. In addition, those few spermatozoa that were recovered were non-motile and had grossly abnormal morphology. Although they still had tails, the sperm heads were rounded and lacked the characteristic hooked shape provided by the acrosome of mouse spermatozoa. The heads were also larger and it appeared that the chromatin was less highly condensed (Fig. 7). Although we have not established the molecular basis for these defects, our results suggest that $\mathrm{Lkb} 1_{\mathrm{S}}$ is required for the process of spermiogenesis. This may reflect a specialized example of the role of LKB1 and AMPK in establishment of cell polarity, since spermiogenesis is one of the most dramatic examples of cell polarisation. However, the possibility that abnormal regulation of one of the other AMPK-related kinases may play a role in this phenotype should also be considered.

We also addressed the question of whether our discovery of the novel splice variant had implications for Peutz-Jeghers syndrome. Almost all of the reported PJS mutations distal to the kinase domain (none of which appear to prevent association with STRAD or MO25 or abolish kinase activity [47]) occur in exon 8, so would affect both $\mathrm{LKB} 1_{\mathrm{L}}$ and $\mathrm{LKB} 1_{\mathrm{S}}$. This includes the P324L, F354L and T367M mutations that have recently been reported to retain the ability to cause growth arrest in G361 cells, while being impaired in activation of AMPK and inhibition of the TOR pathway, and in the induction of polarity in intestinal cells and astrocytes [48]. One possible exception is a mutation that converts codon 416 in exon 9B (AAG, encoding K416) to a TAG stop codon [49], which would remove the last 18 residues of $L K B 1_{L}$ including the Ser-431 phosphorylation site and the farnesylated cysteine. This appeared to cause classical, familial PJS where the patient had multiple intestinal polyps, suggesting that PJS can occur with a mutation that would not affect $\mathrm{LKB} 1_{\mathrm{s}}$. However, it has not been ruled out whether there might have been additional mutations in exon 9A in this case. A related question is whether any PJS mutations might occur in exon 9A. Up to $20 \%$ of subjects with PJS have no known mutation in the LKB1 gene but, prior to this study, exon 9A had not been recognized as an important part of the gene and may not have been sequenced in DNA from PJS subjects. However, sequencing of exon 9A in DNA from 20 individuals where no other mutations have been found did not reveal any new mutations (Virpi Launonen and Lauri Aaltonen, personal communication).

In conclusion, we have discovered a novel splice variant of $L K B 1$, termed $L K B 1_{S}$, that is particularly expressed in early spermatids prior to spermiogenesis, the process in which the highly polarized structures of spermatozoa are formed. Male mice that represent a de facto knockout of 
$\mathrm{Lkb} 1_{\mathrm{S}}$ form very small numbers of polarized spermatozoa that have abnormal heads. Our results suggest that $\mathrm{LKB} 1_{\mathrm{S}}$ has an essential role in spermiogenesis and male fertility.

\section{Acknowledgments}

We thank Dario Alessi for antibodies and helpful discussions, Keith Baar for primers against 18S RNA, Martin Kierans, John James and Calum Thomson at the Centre for High Resolution Imaging and Processing at the University of Dundee for help with scanning EM and histology, and Chris Barratt and Lindsay Tulloch for help with the sperm counts and assays of motility. This study was supported by a Programme Grant from the Wellcome Trust, by Cancer Research UK and Breakthrough Breast Cancer, by the EXGENESIS Integrated Project (LSHM-CT-2004-005272) from the European Commission, and by the pharmaceutical companies that support the Division of Signal Transduction Therapy (AstraZeneca, Boehringer-Ingelheim, GlaxoSmithKline, Merck \& Co. Inc., Merck KGaA and Pfizer). We are very grateful to Virpi Launonen and Lauri Aaltonen for sequencing exon 9A DNA from PJS subjects.

\section{References}

1 Hemminki, A., Markie, D., Tomlinson, I., Avizienyte, E., Roth, S., Loukola, A., Bignell, G., Warren, W., Aminoff, M., Hoglund, P., Jarvinen, H., Kristo, P., Pelin, K., Ridanpaa, M., Salovaara, R., Toro, T., Bodmer, W., Olschwang, S., Olsen, A. S., Stratton, M. R., de la Chapelle, A. and Aaltonen, L. A. (1998) A serine/threonine kinase gene defective in PeutzJeghers syndrome. Nature 391, 184-187

2 Jenne, D. E., Reimann, H., Nezu, J., Friedel, W., Loff, S., Jeschke, R., Muller, O., Back, W. and Zimmer, M. (1998) Peutz-Jeghers syndrome is caused by mutations in a novel serine threonine kinase. Nat. Genet. 18, 38-43

3 Alessi, D. R., Sakamoto, K. and Bayascas, J. R. (2006) Lkb1-dependent signaling pathways. Annu. Rev. Biochem. 75, 137-163

4 Watts, J. L., Morton, D. G., Bestman, J. and Kemphues, K. J. (2000) The C. elegans par-4 gene encodes a putative serine-threonine kinase required for establishing embryonic asymmetry. Development 127, 1467-1475

5 Martin, S. G. and St Johnston, D. (2003) A role for Drosophila LKB1 in anterior-posterior axis formation and epithelial polarity. Nature 421, 379-384

6 Lee, J. H., Koh, H., Kim, M., Kim, Y., Lee, S. Y., Karess, R. E., Lee, S. H., Shong, M., Kim, J. M., Kim, J. and Chung, J. (2007) Energy-dependent regulation of cell structure by AMPactivated protein kinase. Nature 447, 1017-1020

7 Hawley, S. A., Boudeau, J., Reid, J. L., Mustard, K. J., Udd, L., Makela, T. P., Alessi, D. R. and Hardie, D. G. (2003) Complexes between the LKB1 tumor suppressor, STRAD $\alpha / \beta$ and $\mathrm{MO} 25 \alpha / \beta$ are upstream kinases in the AMP-activated protein kinase cascade. J. Biol. 2, 28

8 Shaw, R. J., Kosmatka, M., Bardeesy, N., Hurley, R. L., Witters, L. A., DePinho, R. A. and Cantley, L. C. (2004) The tumor suppressor LKB1 kinase directly activates AMP-activated kinase and regulates apoptosis in response to energy stress. Proceedings of the National Academy of Sciences of the United States of America 101, 3329-3335

9 Woods, A., Johnstone, S. R., Dickerson, K., Leiper, F. C., Fryer, L. G., Neumann, D., Schlattner, U., Wallimann, T., Carlson, M. and Carling, D. (2003) LKB1 is the upstream kinase in the AMP-activated protein kinase cascade. Curr. Biol. 13, 2004-2008 
10 Lizcano, J. M., Göransson, O., Toth, R., Deak, M., Morrice, N. A., Boudeau, J., Hawley, S. A., Udd, L., Mäkelä, T. P., Hardie, D. G. and Alessi, D. R. (2004) LKB1 is a master kinase that activates 13 protein kinases of the AMPK subfamily, including the MARK/PAR-1 kinases. EMBO J. 23, 833-843

11 Jaleel, M., McBride, A., Lizcano, J. M., Deak, M., Toth, R., Morrice, N. A. and Alessi, D. R. (2005) Identification of the sucrose non-fermenting related kinase SNRK, as a novel LKB1 substrate. FEBS Lett. 579, 1417-1423

12 Hardie, D. G. (2007) AMP-activated/SNF1 protein kinases: conserved guardians of cellular energy. Nat. Rev. Mol. Cell Biol. 8, 774-785

13 Inoki, K., Zhu, T. and Guan, K. L. (2003) TSC2 mediates cellular energy response to control cell growth and survival. Cell 115, 577-590

14 Gwinn, D. M., Shackelford, D. B., Egan, D. F., Mihaylova, M. M., Mery, A., Vasquez, D. S., Turk, B. E. and Shaw, R. J. (2008) AMPK phosphorylation of raptor mediates a metabolic checkpoint. Mol. Cell 30, 214-226

15 Imamura, K., Ogura, T., Kishimoto, A., Kaminishi, M. and Esumi, H. (2001) Cell cycle regulation via 53 phosphorylation by a 5'-AMP activated protein kinase activator, 5aminoimidazole- 4-carboxamide-1-beta-d- ribofuranoside, in a human hepatocellular carcinoma cell line. Biochem. Biophys. Res. Commun. 287, 562-567

16 Jones, R. G., Plas, D. R., Kubek, S., Buzzai, M., Mu, J., Xu, Y., Birnbaum, M. J. and Thompson, C. B. (2005) AMP-activated protein kinase induces a p53-dependent metabolic checkpoint. Mol. Cell 18, 283-293

17 Shaw, R. J., Bardeesy, N., Manning, B. D., Lopez, L., Kosmatka, M., DePinho, R. A. and Cantley, L. C. (2004) The LKB1 tumor suppressor negatively regulates mTOR signaling. Cancer Cell 6, 91-99

18 Huang, X., Wullschleger, S., Shpiro, N., McGuire, V. A., Sakamoto, K., Woods, Y. L., McBurnie, W., Fleming, S. and Alessi, D. R. (2008) Important role of the LKB1-AMPK pathway in suppressing tumorigenesis in PTEN-deficient mice. Biochem. J. 412, 211-221

19 Baas, A. F., Kuipers, J., van der Wel, N. N., Batlle, E., Koerten, H. K., Peters, P. J. and Clevers, H. C. (2004) Complete polarization of single intestinal epithelial cells upon activation of LKB1 by STRAD. Cell 116, 457-466

20 Zheng, B. and Cantley, L. C. (2007) Regulation of epithelial tight junction assembly and disassembly by AMP-activated protein kinase. Proceedings of the National Academy of Sciences of the United States of America 104, 819-822

21 Zhang, L., Li, J., Young, L. H. and Caplan, M. J. (2006) AMP-activated protein kinase regulates the assembly of epithelial tight junctions. Proceedings of the National Academy of Sciences of the United States of America 103, 17272-17277

22 Drewes, G., Ebneth, A., Preuss, U., Mandelkow, E. M. and Mandelkow, E. (1997) MARK, a novel family of protein kinases that phosphorylate microtubule-associated proteins and trigger microtubule disruption. Cell 89, 297-308

23 Kishi, M., Pan, Y. A., Crump, J. G. and Sanes, J. R. (2005) Mammalian SAD kinases are required for neuronal polarization. Science 307, 929-932

24 Sapkota, G. P., Deak, M., Kieloch, A., Morrice, N., Goodarzi, A. A., Smythe, C., Shiloh, Y., Lees-Miller, S. P. and Alessi, D. R. (2002) Ionizing radiation induces ataxia telangiectasia mutated kinase (ATM)-mediated phosphorylation of LKB1/STK11 at Thr-366. Biochem. J. 368, 507-516 
25 Sugden, C., Crawford, R. M., Halford, N. G. and Hardie, D. G. (1999) Regulation of spinach SNF1-related (SnRK1) kinases by protein kinases and phosphatases is associated with phosphorylation of the T loop and is regulated by 5'-AMP. Plant J. 19, 433-439

26 Woods, A., Salt, I., Scott, J., Hardie, D. G. and Carling, D. (1996) The $\alpha 1$ and $\alpha 2$ isoforms of the AMP-activated protein kinase have similar activities in rat liver but exhibit differences in substrate specificity in vitro. FEBS Lett. 397, 347-351

27 Goransson, O., McBride, A., Hawley, S. A., Ross, F. A., Shpiro, N., Foretz, M., Viollet, B., Hardie, D. G. and Sakamoto, K. (2007) Mechanism of action of A-769662, a valuable tool for activation of AMP-activated protein kinase. J. Biol. Chem. 282, 32549-32560

28 Baas, A. F., Boudeau, J., Sapkota, G. P., Smit, L., Medema, R., Morrice, N. A., Alessi, D. R. and Clevers, H. C. (2003) Activation of the tumour suppressor kinase LKB1 by the STE20-like pseudokinase STRAD. EMBO J. 22, 3062-3072

29 Altschul, S. F., Madden, T. L., Schaffer, A. A., Zhang, J., Zhang, Z., Miller, W. and Lipman, D. J. (1997) Gapped BLAST and PSI-BLAST: a new generation of protein database search programs. Nucleic Acids Res. 25, 3389-3402

30 Clamp, M., Cuff, J., Searle, S. M. and Barton, G. J. (2004) The Jalview Java alignment editor. Bioinformatics 20, 426-427

31 Sapkota, G. P., Kieloch, A., Lizcano, J. M., Lain, S., Arthur, J. S., Williams, M. R., Morrice, N., Deak, M. and Alessi, D. R. (2001) Phosphorylation of the protein kinase mutated in PeutzJeghers cancer syndrome, LKB1/STK11, at Ser431 by p90(RSK) and cAMP-dependent protein kinase, but not its farnesylation at Cys(433), is essential for LKB1 to suppress cell growth. J. Biol. Chem. 276, 19469-19482

32 Boudeau, J., Deak, M., Lawlor, M. A., Morrice, N. A. and Alessi, D. R. (2003) Heat-shock protein 90 and Cdc37 interact with LKB1 and regulate its stability. Biochem. J. 370, 849-857

33 Pozuelo Rubio, M., Geraghty, K. M., Wong, B. H., Wood, N. T., Campbell, D. G., Morrice, N. and Mackintosh, C. (2004) 14-3-3-affinity purification of over 200 human phosphoproteins reveals new links to regulation of cellular metabolism, proliferation and trafficking. Biochem. J. 379, 395-408

34 Williamson, B. L., Marchese, J. and Morrice, N. A. (2006) Automated identification and quantification of protein phosphorylation sites by LC/MS on a hybrid triple quadrupole linear ion trap mass spectrometer. Mol. Cell. Proteomics 5, 337-346

35 Durocher, Y., Perret, S. and Kamen, A. (2002) High-level and high-throughput recombinant protein production by transient transfection of suspension-growing human 293-EBNA1 cells. Nucleic Acids Res. 30, E9

36 Hardie, D. G., Salt, I. P. and Davies, S. P. (2000) Analysis of the role of the AMP-activated protein kinase in the response to cellular stress. Methods Mol. Biol. 99, 63-75

37 Dale, S., Wilson, W. A., Edelman, A. M. and Hardie, D. G. (1995) Similar substrate recognition motifs for mammalian AMP-activated protein kinase, higher plant HMG-CoA reductase kinase-A, yeast SNF1, and mammalian calmodulin-dependent protein kinase I. FEBS Lett. 361, 191-195

38 Scott, J. W., Norman, D. G., Hawley, S. A., Kontogiannis, L. and Hardie, D. G. (2002) Protein kinase substrate recognition studied using the recombinant catalytic domain of AMP-activated protein kinase and a model substrate. J. Mol. Biol. 317, 309-323 
39 Boudeau, J., Baas, A. F., Deak, M., Morrice, N. A., Kieloch, A., Schutkowski, M., Prescott, A. R., Clevers, H. C. and Alessi, D. R. (2003) MO25a/b interact with STRADa/b enhancing their ability to bind, activate and localize LKB1 in the cytoplasm. EMBO J. 22, 5102-5114

40 Davies, S. P., Carling, D. and Hardie, D. G. (1989) Tissue distribution of the AMP-activated protein kinase, and lack of activation by cyclic AMP-dependent protein kinase, studied using a specific and sensitive peptide assay. Eur. J. Biochem. 186, 123-128

41 Schteingart, H. F., Rivarola, M. A. and Cigorraga, S. B. (1989) Hormonal and paracrine regulation of gamma-glutamyl transpeptidase in rat Sertoli cells. Mol. Cell. Endocrinol, 67, 7380

42 Dufau, M. L., Mendelson, C. R. and Catt, K. J. (1974) A highly sensitive in vitro bioassay for luteinizing hormone and chorionic gonadotropin: testosterone production by dispersed Leydig cells. J. Clin. Endocrinol. Metab. 39, 610-613

43 Meroni, S. B., Riera, M. F., Pellizzari, E. H. and Cigorraga, S. B. (2002) Regulation of rat Sertoli cell function by FSH: possible role of phosphatidylinosito13-kinase/protein kinase B pathway. J. Endocrinol. 174, 195-204

44 Sakamoto, K., McCarthy, A., Smith, D., Green, K. A., Hardie, D. G., Ashworth, A. and Alessi, D. R. (2005) Deficiency of LKB1 in skeletal muscle prevents AMPK activation and glucose uptake during contraction. EMBO J. 24, 1810-1820

45 Bradford, M. M. (1976) A rapid and sensitive method for the quantitation of microgram quantities of protein utilizing the principle of protein-dye binding. Anal. Biochem. 72, 248-254

46 Sakamoto, K., Zarrinpashneh, E., Budas, G. R., Pouleur, A. C., Dutta, A., Prescott, A. R., Ashworth, A., Jovanovic, A., Alessi, D. R. and Bertrand, L. (2005) Deficiency of LKB1 in heart prevents ischemia-mediated activation of AMPKa2 but not AMPKa1. Am. J. Physiol., in press

47 Boudeau, J., Scott, J. W., Resta, N., Deak, M., Kieloch, A., Komander, D., Hardie, D. G., Prescott, A. R., van Aalten, D. M. and Alessi, D. R. (2004) Analysis of the LKB1-STRADMO25 complex. J. Cell Sci. 117, 6365-6375

48 Forcet, C., Etienne-Manneville, S., Gaude, H., Fournier, L., Debilly, S., Salmi, M., Baas, A., Olschwang, S., Clevers, H. and Billaud, M. (2005) Functional analysis of Peutz-Jeghers mutations reveals that the LKB1 C-terminal region exerts a crucial role in regulating both the AMPK pathway and the cell polarity. Hum. Mol. Genet. 14, 1283-1292

49 Wang, Z. J., Churchman, M., Avizienyte, E., McKeown, C., Davies, S., Evans, D. G., Ferguson, A., Ellis, I., Xu, W. H., Yan, Z. Y., Aaltonen, L. A. and Tomlinson, I. P. (1999) Germline mutations of the LKB1 (STK11) gene in Peutz-Jeghers patients. J. Med. Genet. 36, $365-368$ 


\section{FIGURE LEGENDS}

Figure 1: (A) Exon/intron structure of the LKB1 gene and alignment of human, mouse and rat cDNA and EST sequences; (B) alignment of amino acid sequences of the unique $\mathrm{C}$ terminal regions of the short and long forms of LKB1 from human, mouse and rat. (A) the arrangement of exons (E1 through E10) and introns (I1 through I10) of the LKB1 gene are shown at the top, and an alignment of cDNA/EST sequences from human, mouse and rat are shown at the bottom. The diagram is not drawn to scale. Protein coding regions common to both isoforms are shown in grey, while the regions in exons 9A and $9 \mathrm{~B}$ encoding the unique $\mathrm{C}$-terminal regions of $\mathrm{LKB} 1_{\mathrm{S}}$ and $\mathrm{LKB} 1_{\mathrm{L}}$ are shown with different cross-hatching. Database accession numbers are shown at the left. (B) Alignment of the unique amino acid sequences of the C-terminal regions of $L K B 1_{S}$ and $\mathrm{LKB} 1_{\mathrm{L}}$, encoded by exons $9 \mathrm{~A}$ and $9 \mathrm{~B}$, from the human, mouse and rat respectively. Identical residues are marked with grey boxes.

Figure 2: (A) SDS-PAGE analysis of LKB1 purified from rat testis by immunoprecipitation; (B) alignment of predicted amino acid sequences of $L K B 1_{S}$ and $L K B 1_{L}$ with sequence coverage obtained by mass spectrometry. In (A), the five major polypeptides detectable by Coomassie Blue staining were identified by MALDITOF-mass spectrometry of tryptic peptides. In (B), the predicted amino acid sequences of $\mathrm{LKB} 1_{\mathrm{S}}$ and $\mathrm{LKB} 1_{\mathrm{L}}$, derived from the analysis shown in Fig. 1, were aligned. Boxes indicate tryptic peptides whose masses were identified by MALDITOF-mass spectrometry.

Figure 3: Western blotting of LKB1 polypeptides from extracts of (A) rat, (B) mouse and (C) human, and (D) co-precipitation of STRAD $\alpha$ and MO25 $\alpha$ with $L K B 1_{L}$ and $L K B 1_{S}$ from rat testis. Key to tissues: RT, purified rat testis enzyme run in each gel as a marker; Br, brain; He, heart; Li, liver; Te, testis; Ki, kidney; Mu, skeletal muscle; Sp, spleen; Lu, lung; Pa, pancreas. For rat and mouse samples, the amount of extract protein shown beneath each lane was immunoprecipitated using an antibody raised against fulllength recombinant $\mathrm{LKB} 1_{\mathrm{L}}$ prior to Western blotting, whereas for human samples the amount of extract shown was analyzed without prior immunoprecipitation. Blots were probed using an antibody against an N-terminal epitope common to both forms (antiLKB1(N)), or using antibodies againts epitopes in the unique C-terminal regions (anti$\mathrm{LKB} 1_{\mathrm{S}}$ and anti-LKB1 $1_{\mathrm{L}}$ ). The polypeptide labelled "??" is the intermediate band mentioned in the text. For (D), immunoprecipitates were made from rat testis extracts using anti-LKB $1_{\mathrm{L}}$, anti-LKB1 $1_{\mathrm{S}}$ and a control non-immune sheep serum, and analyzed by Western blotting using anti-STRAD $\alpha$ and anti-MO25 $\alpha$ antibodies. 
Figure 4: Activation of endogenous AMPK and AMPK-related kinases in HeLa cells transfected with or without $\mathrm{LKB} 1_{\mathrm{L}}$ or $\mathrm{LKB} 1_{\mathrm{S}}$ plus myc-MO25 $\alpha$ and FLAG-STRAD $\alpha$. (A) Cell lysates were blotted with anti-LKB1 $1_{\mathrm{L}}$, anti-LKB1 $1_{\mathrm{S}}$, anti-myc or anti-FLAG antibodies. (B) The activity of endogenous AMPK was assayed after immunoprecipitation with a mixture of anti-AMPK- $\alpha 1$ and- $\alpha 2$ antibodies, and the phosphorylation and expression of AMPK determined by Western blotting with anti-pT172 and a mixture of antiAMPK- $\alpha 1$ and- $\alpha 2$ antibodies. (C-F) The activities of endogenous SIK1, SIK2, SIK3 and NUAK2 were assayed after immunoprecipitation with anti-SIK1, -SIK2, -SIK3 and -NUAK2 antibodies.

Figure 5: Activation of purified GST fusions of AMPK ( $\alpha 1$ kinase domain, residues 1-312), BRSK1 and BRSK2 by recombinant GST-LKB1:FLAG-STRAD $\alpha$ :myc-MO25 $\alpha$ complexes expressed in HEK-293 cells. (A) Western blotting using the indicated antibodies of HEK293 cell lysates, the initial wash of the glutathione-Sepharose column, and the glutathione eluate; the bottom panel is shows a lower loading of the glutathione eluate probed with anti-GST to show equal recovery of $L K B 1_{L}$ and $L K B 1_{S}$. (B) Activation of bacterially expressed GST-AMPK- $\alpha 1$ kinase domain using various dilutions $(0.1=1$ in 10$)$ of the recombinant LKB1 complexes shown in (A). (C) Phosphorylation of GST-AMPK- $\alpha 1$ kinase domain using 1 in 5 dilutions of the recombinant LKB1 complexes, assessed using anti-pT172 antibody, with anti-GST antibody used for loading controls. (D, F) As (B, C), but using GST-BRSK1 in place of GST-AMPK- $\alpha 1$ kinase domain; (E, G) As (B, C), but using GST-BRSK2 in place of GST-AMPK- $\alpha 1$ kinase domain. The results for B, D and E show mean \pm range of duplicate observations. Where error bars are not visible they lie within the symbol. These experiments were performed twice with very similar results. 
Figure 6: Lack of expression of $L K B 1_{\mathrm{S}}$ in $\mathrm{LKB} 1^{\mathrm{fl} / \mathrm{fl}}$ mice at the (A) RNA and (B) protein level; (C) expression of $\mathrm{LKB} 1_{\mathrm{L}}$ and $\mathrm{LKB} 1_{\mathrm{S}}$ in testis, epididymis and in mature spermatozoa from wild type mice; and expression of $\mathrm{LKB} 1_{\mathrm{S}}$ in whole testis (D) and different testis cell types (E) from rats of different ages. (A) mRNAs encoding $L K B 1_{\mathrm{L}}$ and $\mathrm{LKB} 1_{\mathrm{S}}$, and $18 \mathrm{~S}$ rRNA were amplified by RT-PCR using appropriate primers from testis of wild type (+/+) and floxed (fl/fl) mice; the left-hand lane contains molecular weight markers (M) of the indicated size. (B) Western blots with increasing amounts of total testis protein from wild type $(+/+)$ and floxed (fl/fl) mice; blots were also probed with antiactin antibodies as a loading control. (C) Increasing loadings of extract protein from testis and epididymis, and spermatozoa from wild type mice were analyzed by Western blotting using anti-LKB1 $1_{\mathrm{S}}$, anti-LKB1(N) and anti-actin antibodies. (D) Western blots of testis extracts (30 $\mu \mathrm{g}$ protein) from rats of different ages (d20-d60, 20, 23, 27, 30 and 60 days). (E) Analysis of purified rat testis LKB1, whole testis from 30 day old (d30) and 60 day old (d60) rats, three different preparations of testis germ cells (G1, G2, G3), Leydig cells (LC) and Sertoli cells (SC). Samples contained $60 \mu \mathrm{g}$ of total protein except for the purified rat testis LKB1, which was $20 \mu \mathrm{g}$. Germ cell fractions G1 and G2 were from 26 day old rats and were recovered at the $32-37 \%$ and the $25-32 \%$ Percoll interface respectively. Fraction G3 was from 31 day old rats and was recovered at the 25-32\% Percoll interface. By flow cytometry, the proportions of cells with $4 \mathrm{n}, 2 \mathrm{n}$ and 1n DNA content were G1: 75\%, 19\%, 6\%; G2: 73\%, 11\%, 16\%; G3: 27\%, 10\%, 63\%. The expression of $\mathrm{LKB} 1_{\mathrm{S}}$ therefore correlates with the proportion of haploid cells.

Figure 7: Histology of the cauda of the epididymis, and bright field (BF) microscopy and scanning electron microscopy (EM) of spermatozoa from wild type $(+/+)$ and LKB1 floxed (fl/fl) mice. In the panels third from top, the cells were stained with DAPI to reveal DNA and the pictures represent merged bright field and fluorescence images. The epididymis contains spermatozoa at different stages of maturation, and in some (see upper scanning EM images) the cytoplasmic droplet has not been completely absorbed. Both the histology and the scanning EM were performed with wild type and LKB1 floxed mice of various ages ( 2 months, $\mathrm{n}=2 ; 5$ months, $\mathrm{n}=3 ; 12$ months, $\mathrm{n}=1$ ). The results were very similar in every case. The scanning EM pictures are representative of several spermatozoa examined from each epididymis, although the number recovered from the the LKB1 floxed animals was small. 


\section{Towler et al Figure 1A}
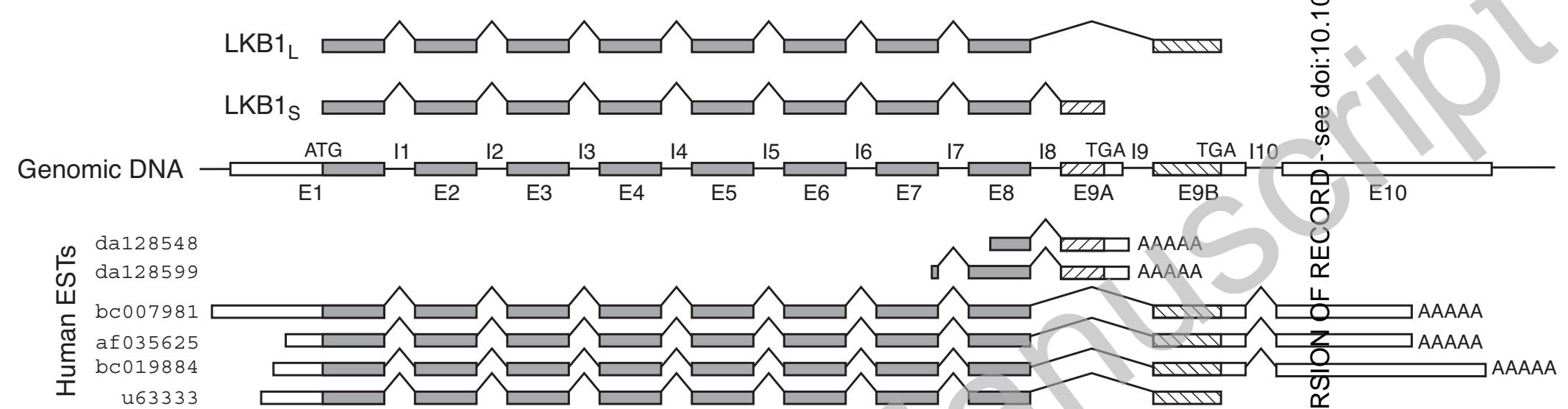

Cf729609

bg296171

œ cd56546

ш ab015801

Ф) af129870

을 af145287

af151711

bc052379

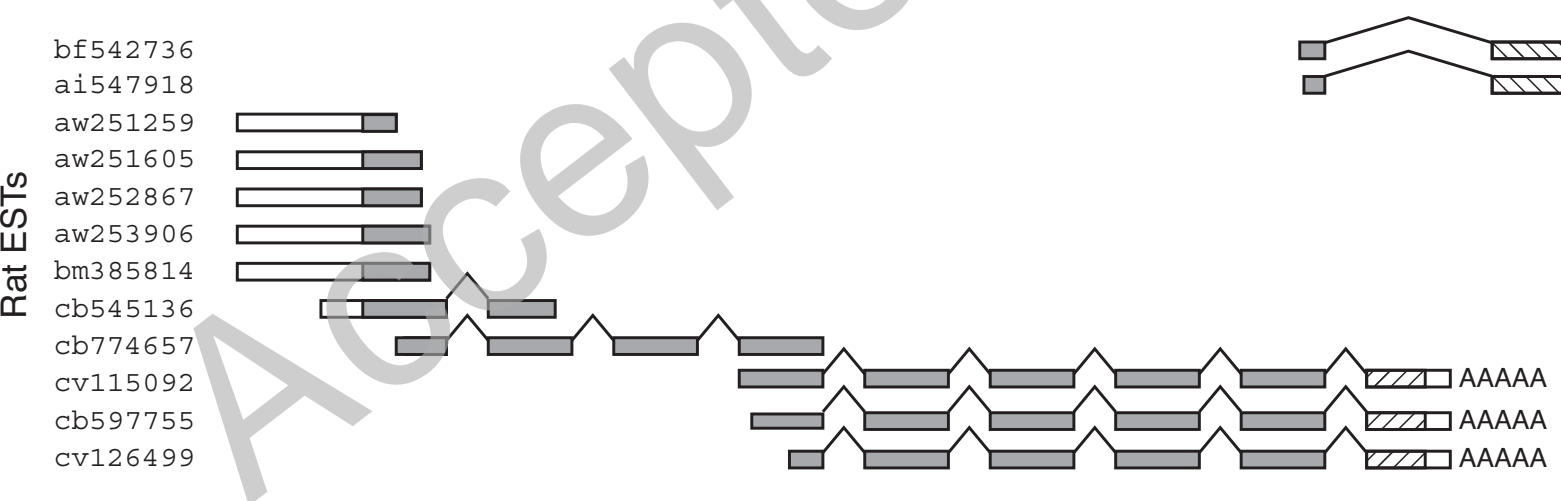

Licenced copy. Copying is not permitted, except with prior permission and as allowed by law.

(C) 2008 The Authors Journal compilation (c) 2008 Biochemical Society 


\section{Towler et al Figure 1B}

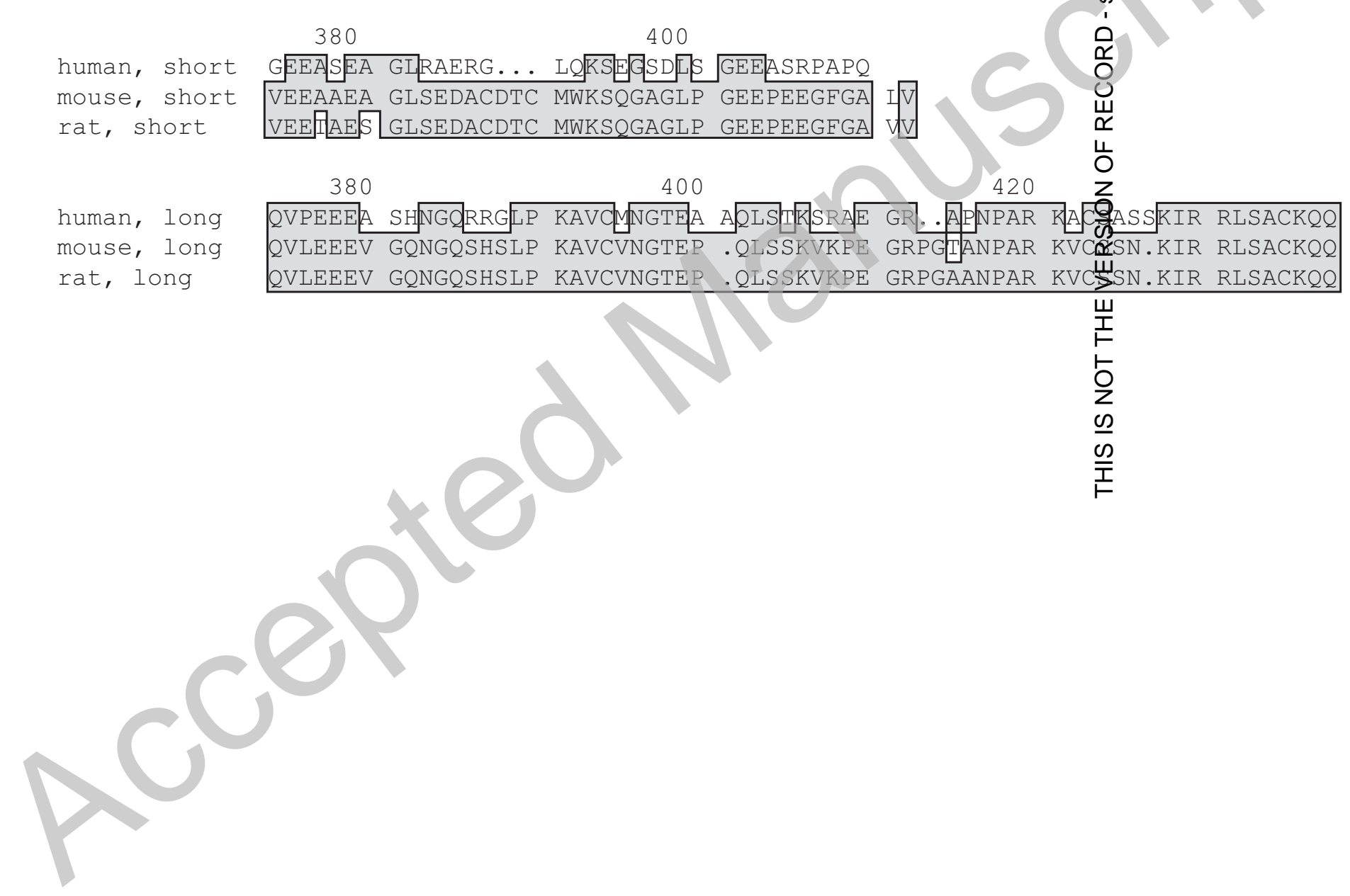

Licenced copy. Copying is not permitted, except with prior permission and as allowed by law.

(C) 2008 The Authors Journal compilation (C) 2008 Biochemical Society 


\section{Towler et al Figure 2}

\section{A) Stained gel of rat testis LKB1 preparation

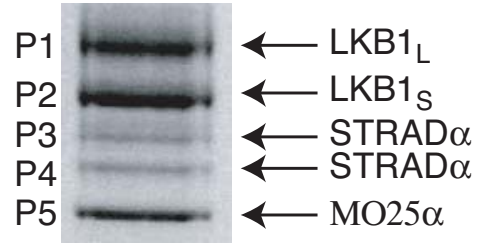

B) Alignment of $L K B 1_{S} / L K B 1_{L}$ showing sequence coverage

1
MDVADPQPLG LFPEGELMSV GMDTFIHR ID STEVIYQPRR KRAKLIGKYL MDVADPQPLG LFPEGELMSV GMDTFIHR ID STEVIYOPAR KRAKLIGKYL

$51 \quad 100$ MGDLLGEGSY GKVKEVLDSE TLCBRAVKIL KKKKLRRIPN GEANVKKEIO 101

LLRRLRHANV IQLVDVLYNE EKRKMYMVME YCVCGMQEML DSVPEK/ LLRRLAHANV IQLVDVLYNE EKQRMYMVME YCVCGMQEML DSVPEKAFPV \begin{tabular}{lr}
151 & 200 \\
\hline COAHGYFROL IDGLEYLHSO & GIVHKDIKPG NLLLTTNGTL KISDLGVAEA
\end{tabular} CQAHGYFRQL IDGLEYLHSQ GIVHKDIKPG NLLLTTNGTL KISDLGVAEA

\begin{tabular}{llr}
201 & & 250 \\
\hline LHPFAVDDTC RTSQGSPAFO PPEIANGLDT & FSGFKVDIWS AGVTLYNITT \\
\hline
\end{tabular} LHPFAVDDTC ATSOGSPAFO PPEIANGLDT FSGEKVDIWS AGVTLYNITT

$251 \quad 300$ GLYPFEGDNI YKLFENIGRG DFTIPCDCAP PLSDLLAGML EYEPAKRFSI

$301 \quad 350$

RQIP QHSWFR K/ KHPLAEALV PIPPSPDTKD RWR SMTVVPY LEDLHGRAEE

RQIRQHSWFR 四HAPLAEALV PIPPSPDTKD RWR SMTVVPY LEDLHGRAEE

3514400

EEDEDIFDIE DGIIYTQDFT VPGQVLEEEV GQNGQSHSLP KAVCVNGTEP

EEDEDLFDIE DGIIYTQDFT VPGVEETAES GLSEDACDTC MWKSOGAGLP

401

436

OLSSKVKPEG RPGAANPARK VCSSNKIRRL SACKOO

GEEPEEGFGA VV

Licenced copy. Copying is not permitted, except with prior permission and as allowed by law. (c) 2008 The Authors Journal compilation (c) 2008 Biochemical Society 


\section{Towler et al Figure 3}

A) Western blots of rat anti-LKB1 immunoprecipitates

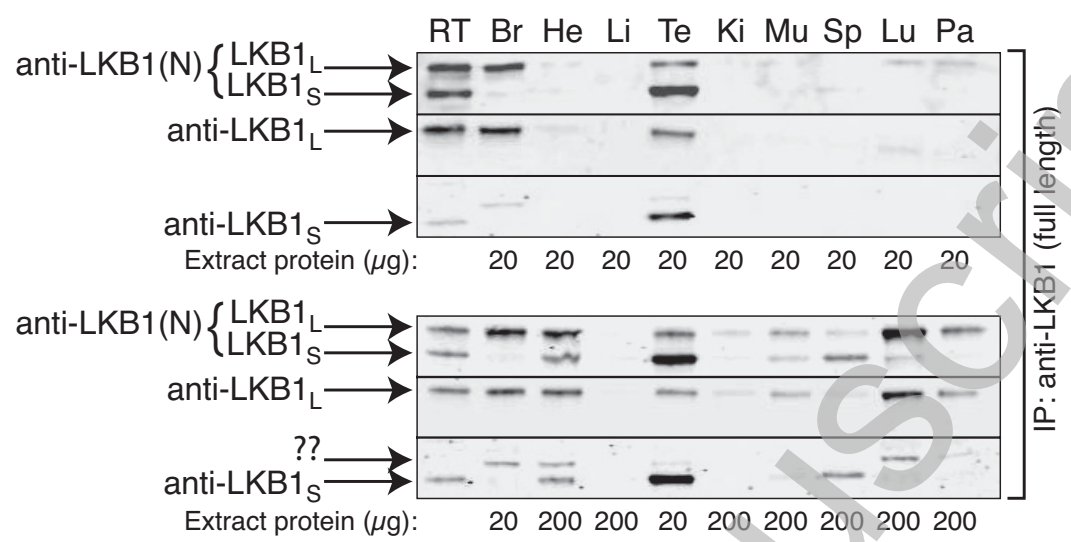

B) Western blots of mouse anti-LKB1 immunoprecipitates

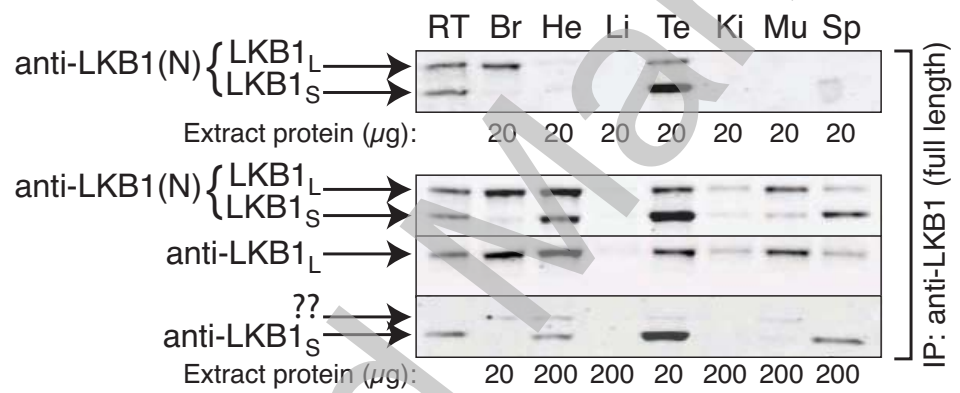

C) Western blots of human extracts

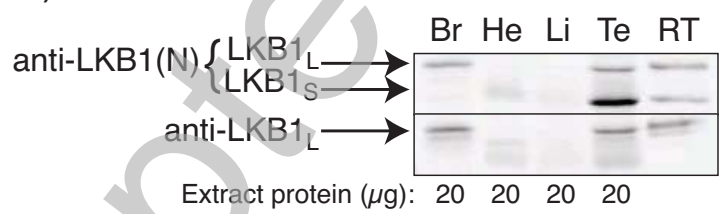

D) Western blots of rat testis immunoprecipitates

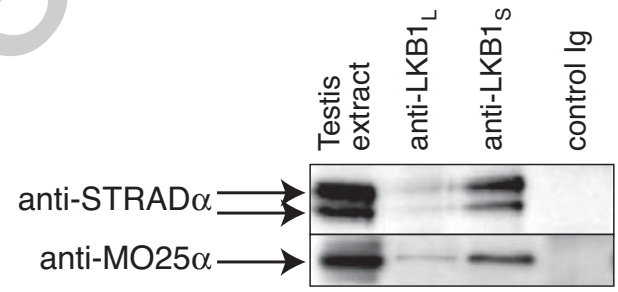




\section{Towler et al Figure 4}

A) Expression of LKB1, STRAD, MO25

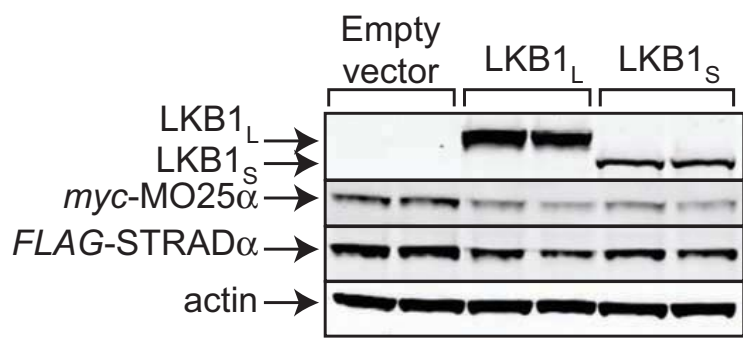

C) Activation of SIK1 (SIK)

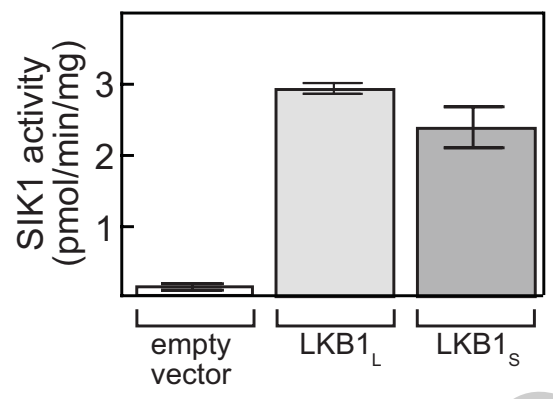

E) Activation of SIK3 (QSK)

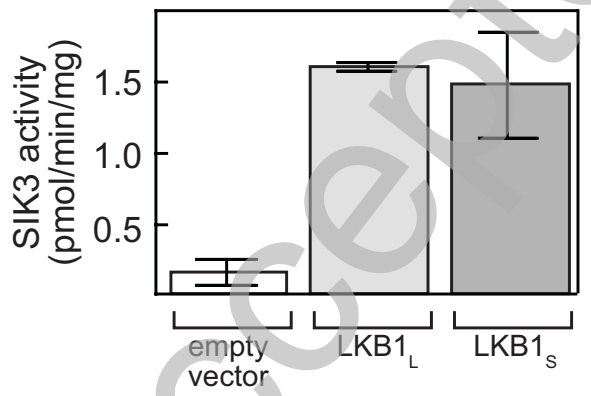

B) Activation/phosphorylation of AMPK

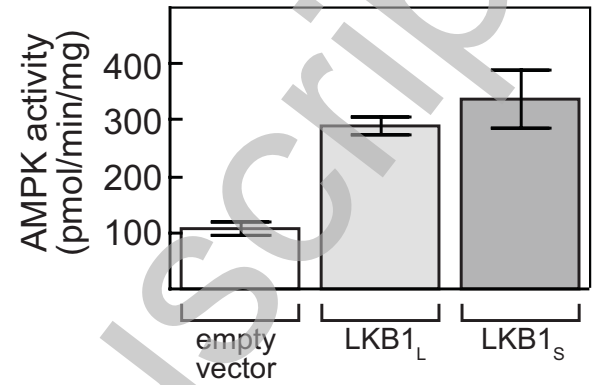

$\mathrm{pT} 172 \rightarrow$

AMPK- $\alpha 1 / \alpha 2 \rightarrow \longrightarrow$

D) Activation of SIK2 (QIK)

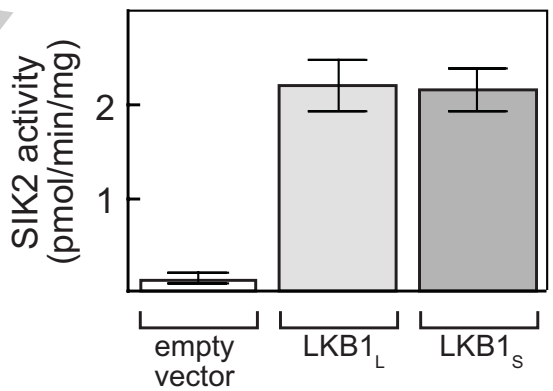

F) Activation of NUAK2 (SNARK)

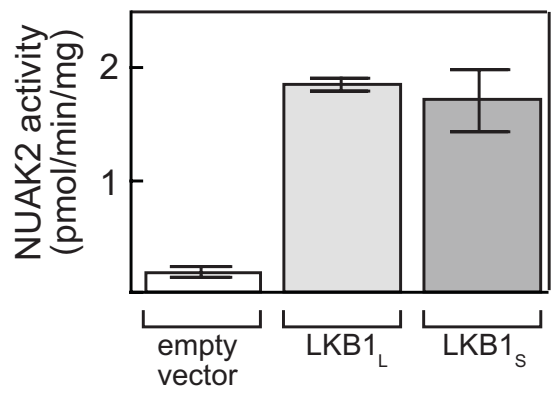




\section{Towler et al Figure 5}

\section{A) Purification of LKB1:STRAD:MO25 \\ B) Activation of GST- $\alpha 1$ kinase domain}

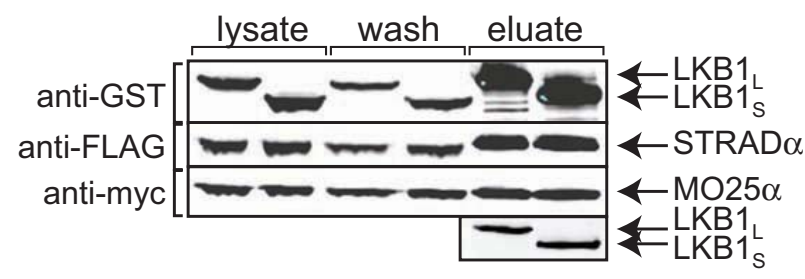

C) Phosphorylation of GST- $\alpha 1$ kinase domain
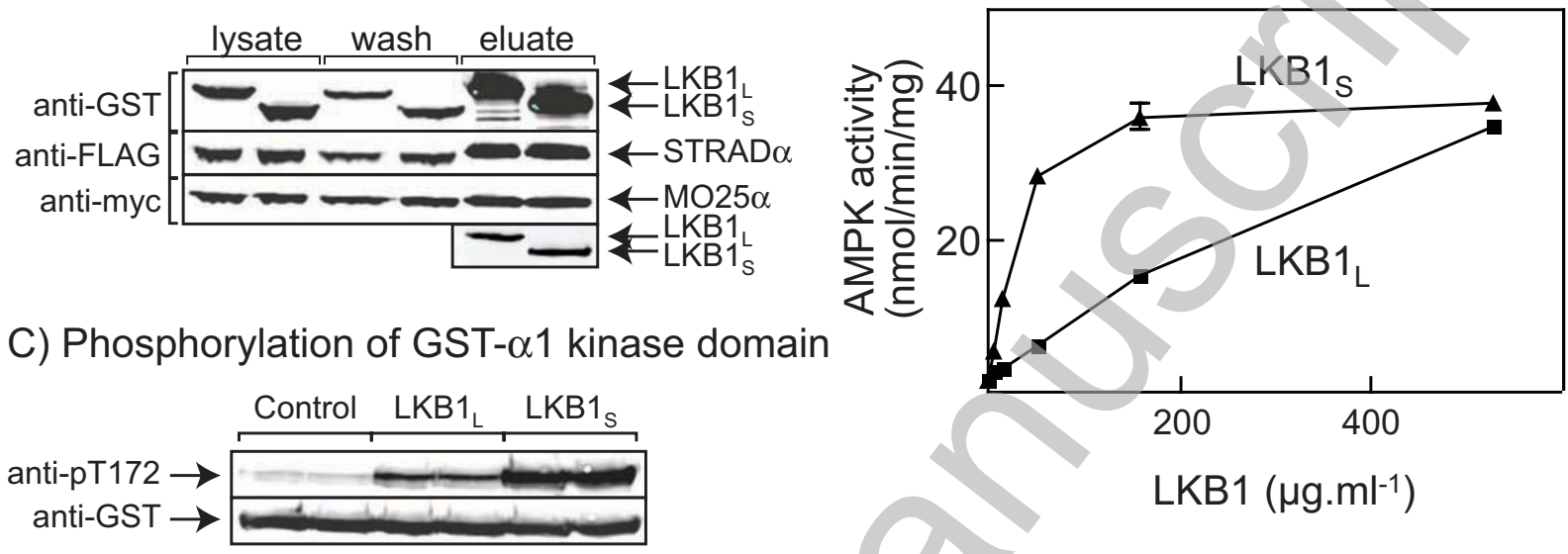

D) Activation of GST-BRSK1

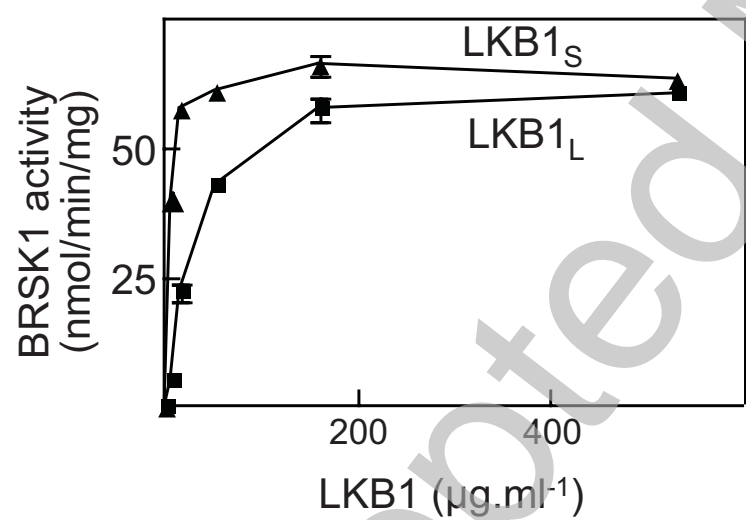

F) Phosphorylation of GST-BRSK1

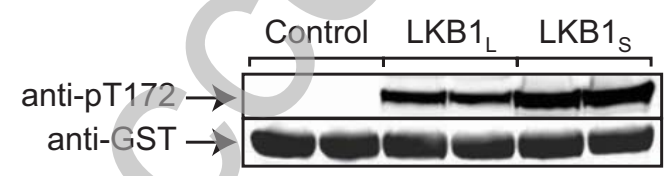

E) Activation of GST-BRSK2

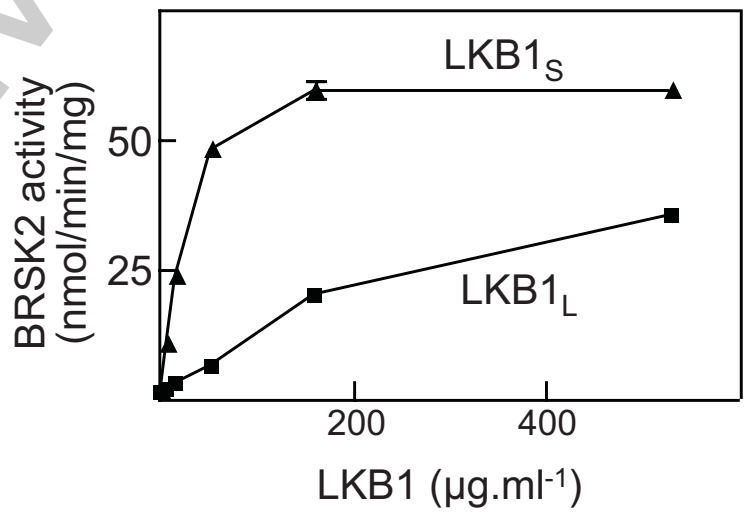

G) Phosphorylation of GST-BRSK2

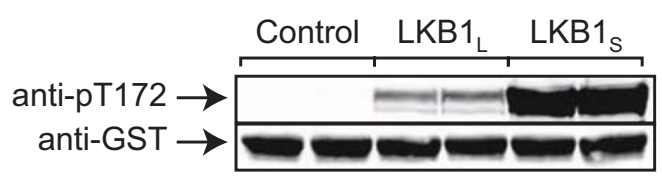




\section{Towler et al Figure 6}

A) RT-PCR of testis RNA from wt and floxed mice

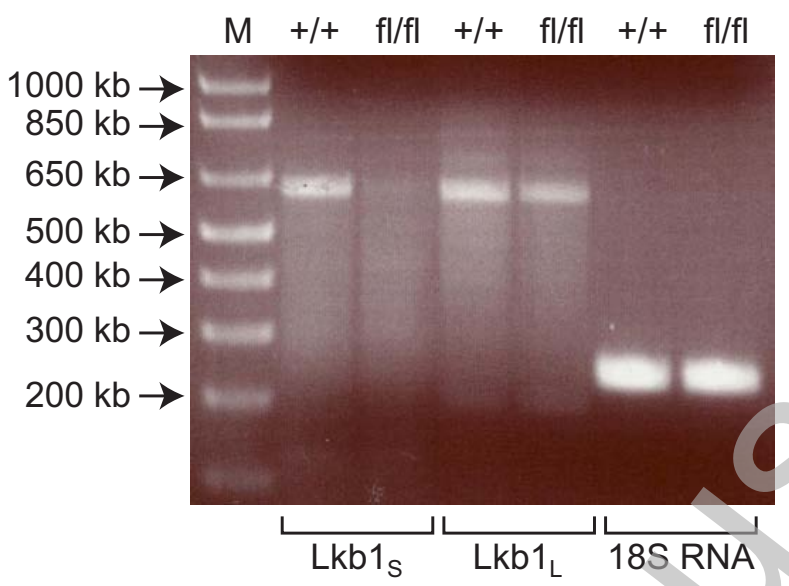

B) Western blots of testis protein from wt and floxed mice

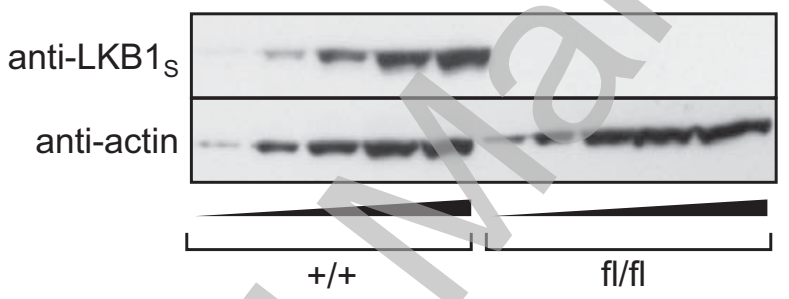

C) Western blots of different regions

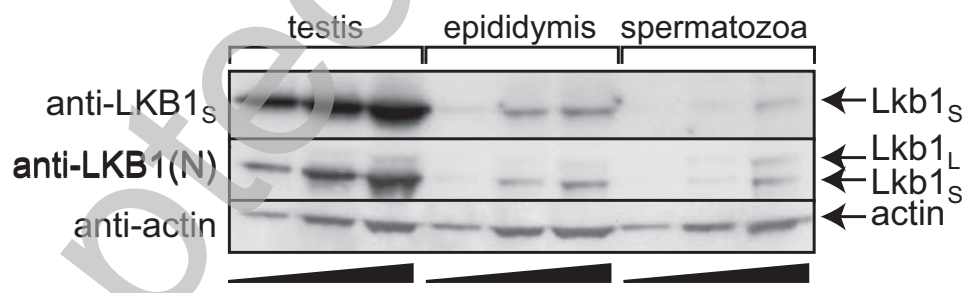

D) Western blots of rat testis from different ages d20 d23 d27 d30 d60

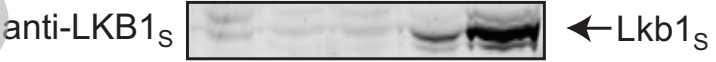

E) Western blots of rat testis and testis cell types

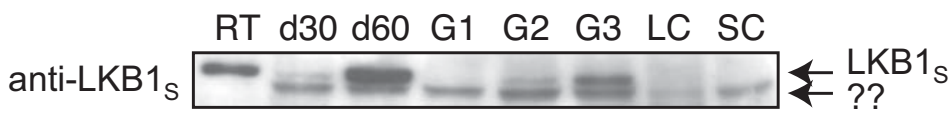




\section{Towler et al Figure 7}
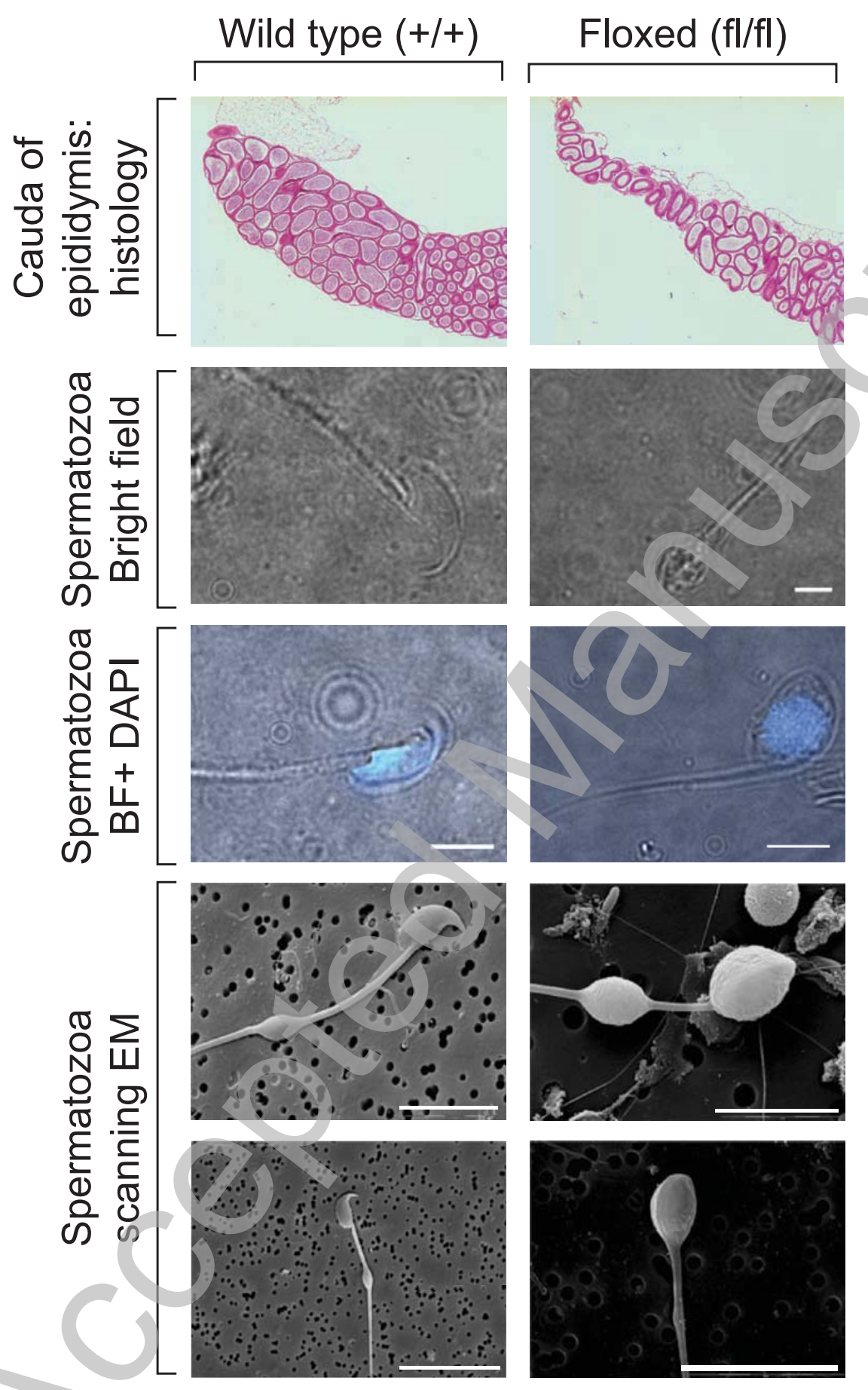